\title{
An Improved Maximum Power Point Approach for Temperature Variation in PV System Applications
}

\author{
Abdelkhalek Chellakhi $\mathbb{D}^{1},{ }^{2}$ Said El Beid $\mathbb{D}^{2},{ }^{2}$ and Younes Abouelmahjoub ${ }^{1}{ }^{1}$ \\ ${ }^{1}$ National School of Applied Sciences, LabSIPE, Chouaib Doukkali University, El Jadida 24000, Morocco \\ ${ }^{2}$ CISIEV Team, Cadi Ayyad University, Marrakech 40160, Morocco \\ Correspondence should be addressed to Abdelkhalek Chellakhi; chellakhi.a@ucd.ac.ma
}

Received 3 March 2021; Accepted 9 May 2021; Published 11 June 2021

Academic Editor: Huiqing Wen

Copyright (C) 2021 Abdelkhalek Chellakhi et al. This is an open access article distributed under the Creative Commons Attribution License, which permits unrestricted use, distribution, and reproduction in any medium, provided the original work is properly cited.

\begin{abstract}
This paper develops and discusses an improved MPPT approach for temperature variation with fast-tracking speed and reduced steady-state oscillation. This MPPT approach can be added to numerous existing MPPT algorithms in order to enhance their tracking accuracy and response time and to reduce the power loss. The improved MPPT method is fast and accurate to follow the maximum power point under critical temperature conditions without increasing the implementation complexity. The simulation results under different scenarios of temperature and insolation were presented to validate the advantages of the proposed method in terms of tracking efficiency and reduction of power loss at dynamic and steady-state conditions. The simulation results obtained when the proposed MPPT technique was added to different MPPT techniques, namely, perturb and observe (P\&O), incremental conductance (INC), and modified MPP-Locus method, show significant enhancements of the MPP tracking performances, where the average efficiency of the conventional P\&O, INC, and modified MPP-Locus MPPT methods under all scenarios is presented, respectively, as $98.85 \%, 98.80 \%$, and $98.81 \%$, whereas the average efficiency of the improved P\&O, INC, and modified MPP-Locus MPPT methods is $99.18 \%$, 99.06\%, and $99.12 \%$, respectively. Furthermore, the convergence time enhancement of the improved approaches over the conventional P\&O, INC, and modified MPP-Locus methods is 2.06, 5.25, and 2.57 milliseconds, respectively; besides, the steady-state power oscillations of the conventional $\mathrm{P} \& \mathrm{O}$, INC, and modified MPP-Locus MPPT methods are 2, 1, and 0.6 watts, but it is neglected in the case of using the improved approaches. In this study, the MATLAB/Simulink software package was selected for the implementation of the whole PV system.
\end{abstract}

\section{Introduction}

The demand for electric energy has been increasing in recent years; in this sense, there are many sources to produce it, but there are also constraints related to its production, such as the effect of pollution and warming global climate. These constraints lead research towards the development of renewable and nonpolluting energy sources. Photovoltaic solar energy is certainly one of the most adequate sources of renewable energy [1]. Solar panels, although they are more efficient, have yields that remain quite low. This is why we must exploit the maximum power that they can generate by minimizing energy losses. An important feature of these panels is that the maximum available power is provided only at a single operating point called the maximum power point
(MPP), defined by a given voltage and current; this point moves according to the weather conditions (sunshine, ambient temperature, etc.). The impact of ambient temperature changes on the performance and efficiency of the PV cell is one of the important effects; as a result, the PV cell's performance and its efficiency degrade with an increase in the ambient temperature. Therefore, the performance degradation of the PV cell under the temperature effect can be seen in the PV cell's characteristics, like open-circuit voltage $\left(V_{\mathrm{oc}}\right)$, saturation current $\left(I_{\mathrm{sc}}\right)$, fill factor $(\mathrm{FF})$, and efficiency $(\eta)$. According to many studies [2,3], $V_{\text {oc }}$ decreases with increasing $T$ whereas $I_{\mathrm{sc}}$ increases slightly with increasing $T$. Both $\mathrm{FF}$ and $\eta$ decrease when the ambient temperature increases, and efficiency degradation is largely due to a decrease in $V_{\text {oc }}$. In addition, other parameters are affected by the temperature, 


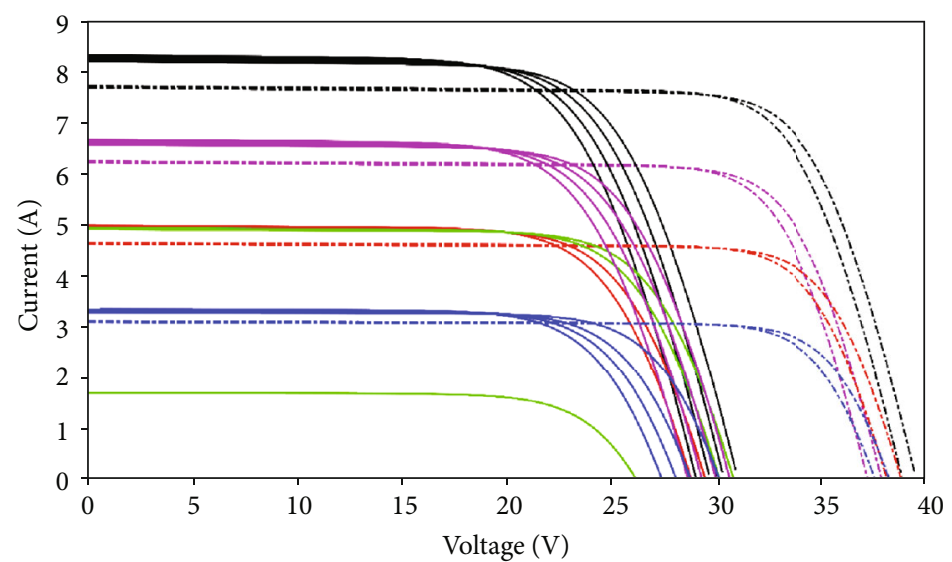

(a)

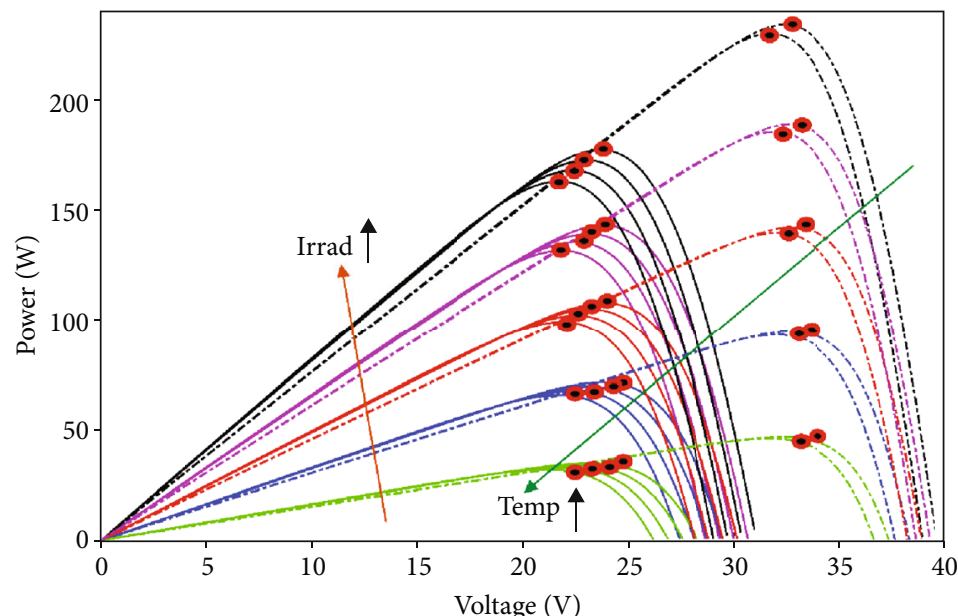

$-1000 \mathrm{~W} / \mathrm{m}^{2}$ at high tem
$-800 \mathrm{~W} / \mathrm{m}^{2}$ at high temp
$-600 \mathrm{~W} / \mathrm{m}^{2}$ at high temp
$-400 \mathrm{~W} / \mathrm{m}^{2}$ at high temp
$-200 \mathrm{~W} / \mathrm{m}^{2}$ at high temp
$--1000 \mathrm{~W} / \mathrm{m}^{2}$ at low temp

- - $800 \mathrm{~W} / \mathrm{m}^{2}$ at low temp

- . $600 \mathrm{~W} / \mathrm{m}^{2}$ at low temp

_ _ $400 \mathrm{~W} / \mathrm{m}^{2}$ at low temp

$200 \mathrm{~W} / \mathrm{m}^{2}$ at low temp

- MPP

(b)

FIgURE 1: PV module output characteristics with different temperature variability effects and under different solar radiation levels: (a) $I-V$ characteristics and (b) $P-V$ characteristics.

like series resistance $\left(R_{\mathrm{s}}\right)$, shunt resistance $\left(R_{\mathrm{sh}}\right)$, reverse saturation current density $\left(J_{0}\right)$, and ideality factor $(n)$. The variation of $R_{\mathrm{s}}$ and $R_{\mathrm{sh}}$ with temperature affects slightly the efficiency, while an exponential increase in $I_{\mathrm{o}}$ with increasing $T$ decreases $V_{\text {oc }}$ rapidly. Hence, those parameters control the temperature effect on $V_{\text {oc }}, \mathrm{FF}$, and $\eta$ of the PV cell [2].

In conclusion, when the performance of the PV cell degrades with the increase of the temperature, the power extracted from the PV cell degrades too, and the temperature variations leading to maximum power point (MPP) change. Thus, the temperature impact can be reduced by the exploitation of the maximum power available from the PV cell.

Extracting the maximum power requires a tracking mechanism of this point called MPP tracking (MPPT) [4]. Therefore, in order to harvest the maximum power output and improve the efficiency of the entire PV system, many maximum power point tracking (MPPT) approaches have been proposed in the literature $[5,6]$. Perturb and observe $(\mathrm{P} \& \mathrm{O})[7,8]$ and incremental conductance (INC) [9] are the most commonly used techniques due to their low cost and easy implementation. Nevertheless, these methods show obvious drawbacks, such as low tracking efficiency under sudden variation of solar irradiation and oscillations around the maximum power points (MPPs) during the steady-state procedure [10]. Originated from these basic methods, many modified MPPT controllers, such as modified adaptive hill climbing (MAHC) [11], variable step size incremental conductance (VSSINC) [12], and incremental resistance (INR), have been proposed. However, the dilemma between the transient operations and amplitude of steady-state oscillations has not been solved perfectly [11]. Furthermore, the implementation of the control becomes difficult [13]. And further parameters like variable step size are proposed, and 


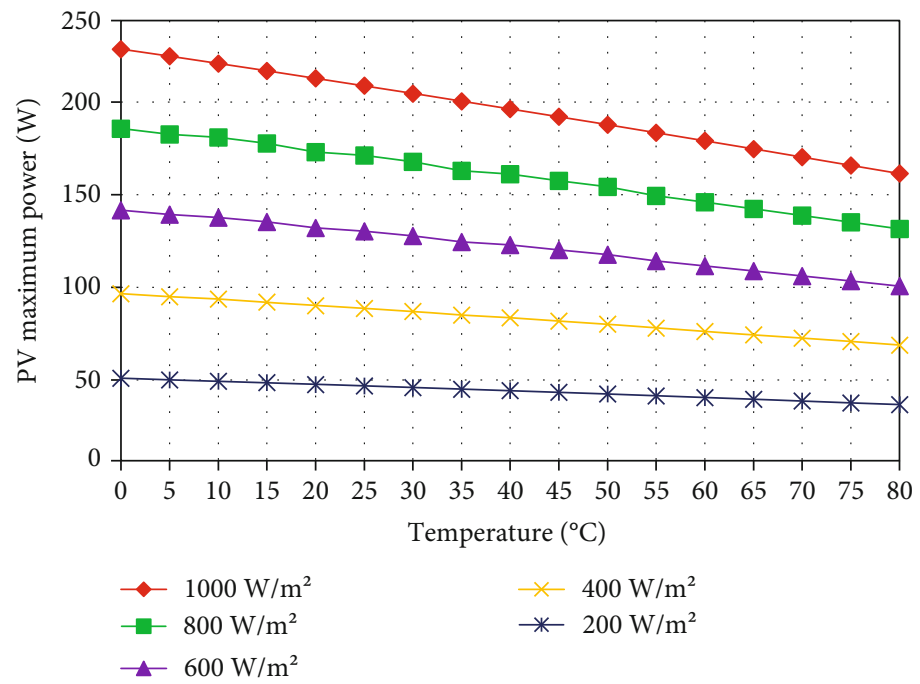

FIGURE 2: Maximum power variations with temperature changes under different radiation levels.

the optimal parameter must be determined to ensure better accuracy $[12,14]$.

Faster and more accurate MPPT algorithms, such as Beta algorithm $[15,16]$, particle swarm optimization (PSO) algorithm $[17,18]$, fuzzy logic controller (FLC) algorithm [18], MPP-Locus algorithm [19], and modified MPP-Locus algorithm [14], have been introduced. These MPPT techniques exhibit better effectiveness than other classical methods, especially under varying solar irradiation conditions.

In the all-existing classical and modern MPPTs, strategies rarely take into account the temperature variation effect, which limits their performance and reduces the global efficiency of the PV system. Many control calculations use temperature as an analysis parameter to recognize MPPT. For example, the authors in Ref. [20] proposed a combination of MPPT temperature calculation and PV cooling system, where the PV module temperature was utilized to calculate the optimum voltage in order to extract the maximum power point (MPP). Reference [21] presents a recent publication named variable universe fuzzy logic control (VUFLC) based on the fuzzy logic control with 25 rules. The suggested VUFLC-temperature MPPT technique selects scalable factors with respect to the dynamic variation of temperature by combining the temperature coefficient (TC) characteristic of the PV modules in order to enhance the tracking performance [21]. The implementation complexity is the worst drawback of the proposed VUFLC MPPT controller, where the fuzzy logic controller requires detailed knowledge and large memory for the implementation of the 25 rules.

To deal with this problem, a novel MPPT approach is suggested in this paper, which can be easily added to many MPPT algorithms in order to improve their MPP tracking efficiency in various climatic conditions, especially under temperature variation as explained and discussed in our previous published work [22], where the proposed MPPT method has easily and successfully added to a previous novel published MPPT technique and the simulation results prove that the proposed MPPT method has significant enhancement of the tracking accuracy and reduction of the power



FIgURE 3: Schematic diagram of the complete PV system.

loss, without increasing the implementation complexity of the PV system [22].

In this context, this paper is an extension of the previous work, in which the proposed MPPT approach has been successfully added to three MPPT algorithms, namely, P\&O, INC, and modified MPP-Locus method in [14]. Different scenario conditions of temperature and solar irradiation are adopted to examine the performances of the improved MPPT tactic using MATLAB/Simulink environment. Based on the simulation results, better efficiency and good accuracy have been obtained when using the improved MPPT approach. In this respect, the latter has higher tracking speed, lower steady-state oscillation, and better power loss mitigation.

The remaining of the paper is as follows. Section 2 discusses the temperature effect on the PV panel. Section 3 presents the MPPT methods. Next, the MPPT tracking efficiency and simulation results are described in Sections 4 and 5, respectively. Finally, the conclusion of the study is reported in Section 6.

\section{Temperature Effect on the PV Panel Characteristics}

The PV generator consists of numerous solar cells, where the solar cell or PV cell is a device that converts the light energy 
into electrical energy based on the principles of the photovoltaic effect. The PV cell performance is highly dependent on temperature changes. The latter will affect the power energy generated from the PV solar cells, and the PV voltage is highly dependent on the temperature; an increase in temperature will decrease significantly the PV cell open-circuit voltage [23-25].

Figure 1 shows the effect of ambient temperature on $I-V$ and $P-V$ curves of the PV panel at different irradiations. As can be seen, the nonlinearity relation between the PV panel output parameters and the atmospheric variables is highly dependent on the insolation level and ambient temperature changes.

The PV cell short-circuit current $\left(I_{\mathrm{sc}}\right)$ increases quasilinearly with the rise of the solar radiation while the PV cell open-circuit voltage increases slightly, and the PV cell maximum electrical power is highly proportional to the solar radiation.

With increasing temperature, PV current increases slightly, but PV open-circuit voltage $\left(V_{\mathrm{oc}}\right)$ decreases clearly as shown in Figure 1(a). In addition, Figure 1(b) indicates that the output power of the photovoltaic module decreases rapidly with the huge increase in temperature with constant insolation. It is noticeable from Figure 1(b) that when the ambient temperature varies from a lower level to a higher level, the maximum output power (MPP) generated from the PV module under uniform radiation decreases strongly.

Figure 2 shows the temperature effect on the maximum output power of the PV module under different solar radiations, where a strong decrease in the maximum output power in terms of the increase of temperature is noticeable. On the other hand, high temperature can affect the generated power and the efficiency of PV cells due to the increasing internal resistance of solar cells [26].

\section{Maximum Power Point Search Algorithms}

The role of several MPPT techniques suggested till date is to regulate the duty ratio $(d)$ of the DC-DC converter used in order to extract the real MPP of the PV panel. This purpose is reached when the actual load line as seen by the PV panel matches with that of a load at which available maximum power is extracted from the PV panel [27]. Four conventional types of DC-DC converters are mostly used for this purpose, namely, Boost, Buck, Buck-Boost, and Cuk converters. For grid-connected systems or for AC loads generally, an inverter is used after a DC-DC converter, but with the scientific research advancement, one stage is eliminated, and the DC output of the PV panel is directly converted to AC [28]. Figure 3 shows the schematic diagram of a PV system with a DC-DC converter. $R_{\text {in }}$ and $R_{\text {out }}$ are the input and output resistance seen by the DC-DC converter, respectively [27].

3.1. Principle of the PঊO Method. Thanks to its simplicity, ease of implementation, and low cost, perturb and observe $(\mathrm{P} \& \mathrm{O})$ MPPT technique is the most widely used in the commercial PV system. Its principle is based on the PV voltage perturbation regarding the comparison of the extracted PV power [29]. If the variation of the direction is positive and

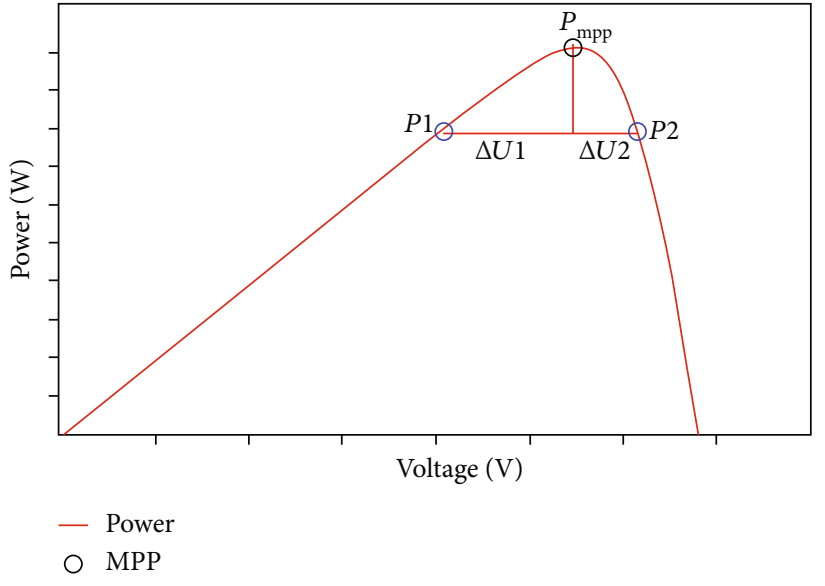

Figure 4: Tracking issues in the $P-V$ curve.



FIgURE 5: Flowchart of the basic perturb and observe (P\&O) tactic.

the PV output voltage increases, the MPPT technique continues the perturbation in this direction; if the PV output power decreases, in the next perturbation, the direction will be reversed [29].

Figure 4 shows the characteristic $P-V$ curve, where $P_{\text {mpp }}$ is the MPP, $P 1$ is to the left of the MPP, $P 2$ is to the right of the MPP, and $\Delta U 1$ and $\Delta U 2$ are the changing ranges of the output voltage. To achieve the MPP, $\Delta U 1$ should be increased in $P 1$, but $\Delta U 2$ should be decreased in $P 2$. In this case, $\Delta U 1$ and $\Delta U 2$ differ, and $\Delta U 1>\Delta U 2$. A greater distance from the MPP yields a greater difference between $\Delta U$ 1 and $\Delta U 2$ owing to the existence of perturbation; it is very hard for the conventional $\mathrm{P} \& \mathrm{O}$ algorithm to eliminate the ripple problem at the MPP. The step size of the perturbation directly affects the performance of the MPPT. All of these elements cause power loss [29]. Figure 5 presents the flowchart of the conventional $\mathrm{P} \& \mathrm{O}$ method. 


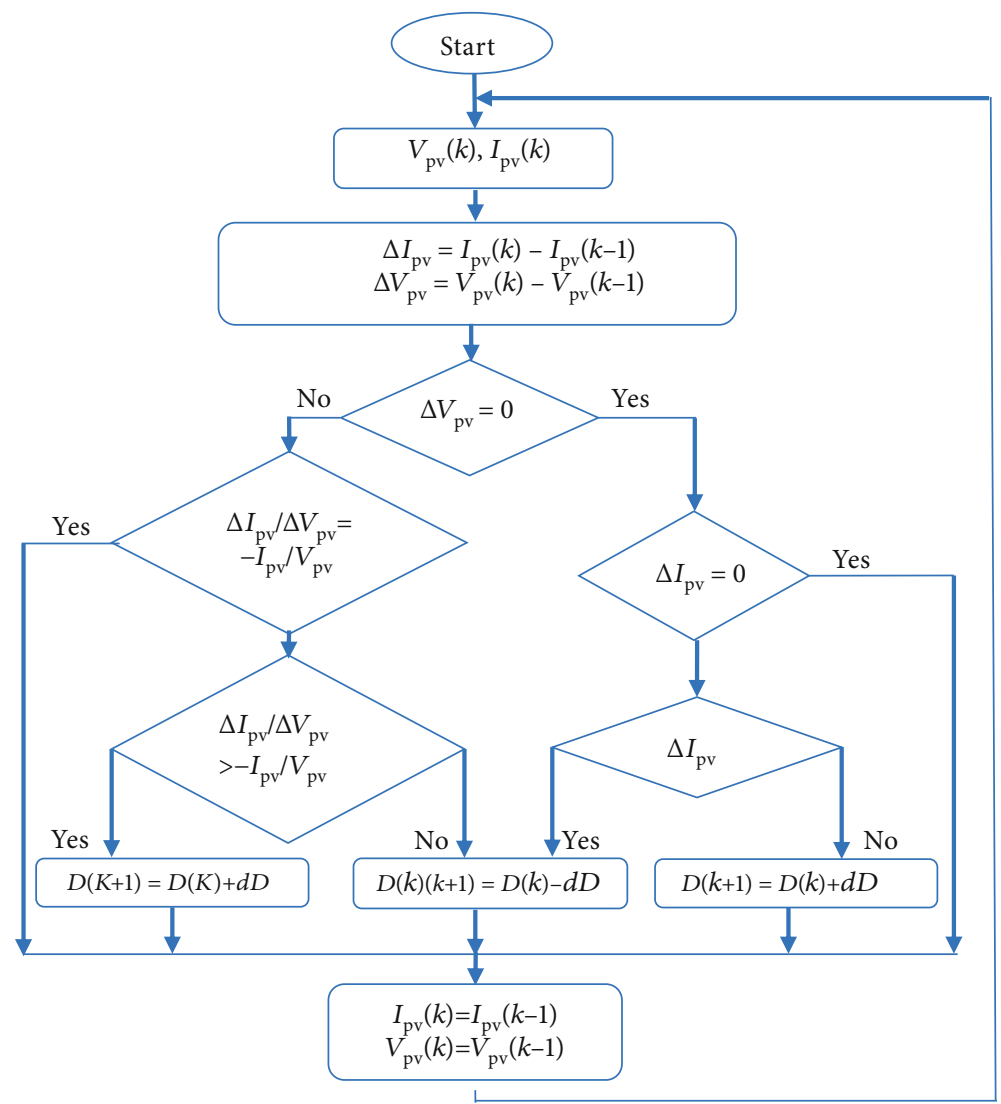

FIGURE 6: Flowchart of the basic INC algorithm.

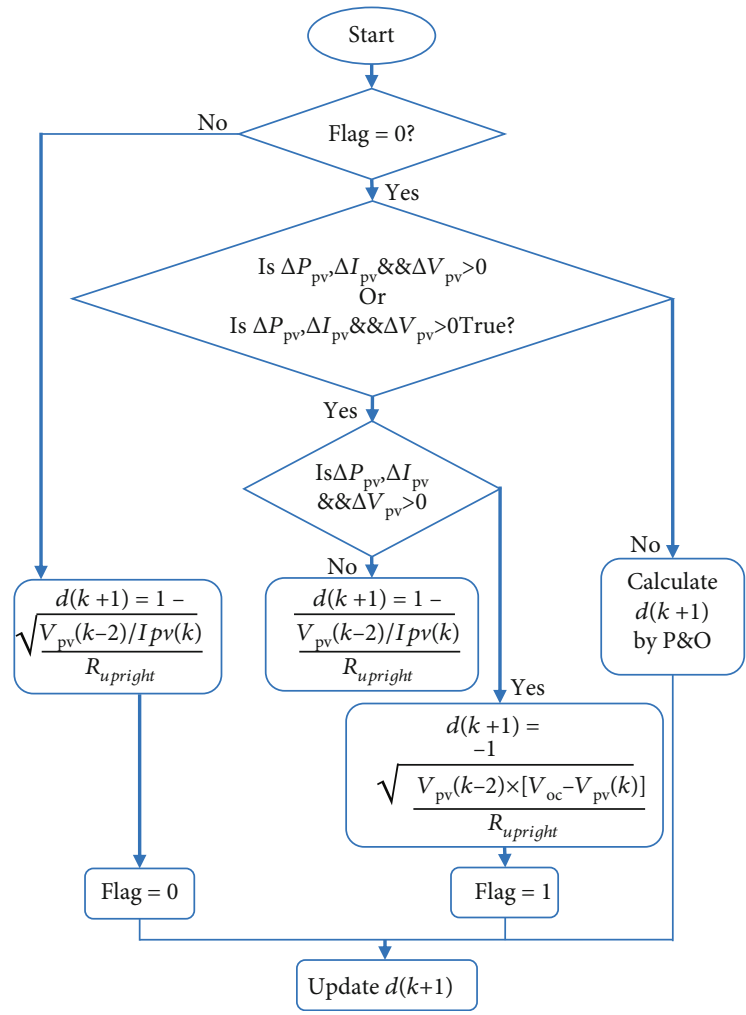

Figure 7: Flowchart of the modified MPPT method based on the MPP-Locus technique.

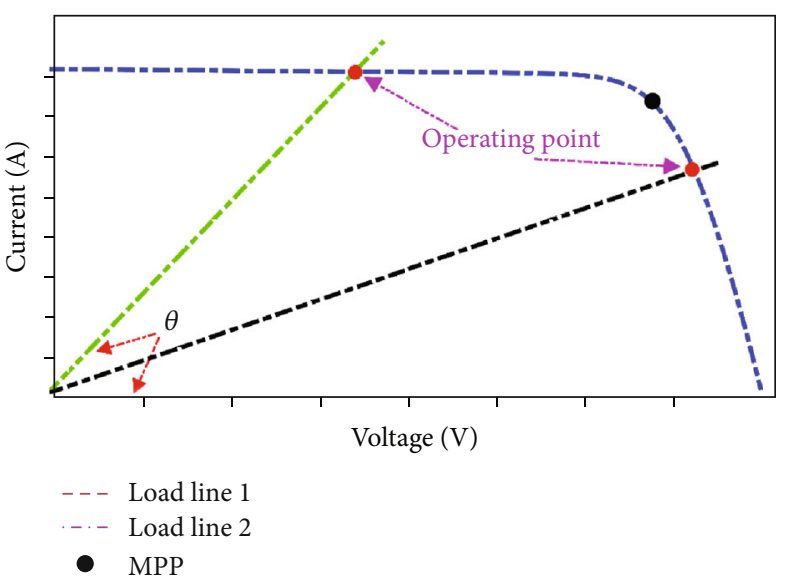

FIgURE 8: Operating point resulted by a PV module connected with a DC-DC converter.

3.2. Principle of the INC Method. The incremental conductance (INC) algorithm's principle to track the real MPP is based on the slope $d l_{\mathrm{pv}} / d V_{\mathrm{pv}}$ of the PV array power curves, which is zero at the MPP, negative at the right of MPP, and positive at the left of the MPP [13].

The maximum output power $P_{\mathrm{MPP}}=V_{\mathrm{MPP}} * I_{\mathrm{MPP}}$ is obtained by differentiating the PV output power with respect to voltage and setting the result to zero: 


$$
\frac{d P_{\mathrm{pv}}}{d V_{\mathrm{pv}}}=I_{\mathrm{pv}}+V_{\mathrm{pv}} \frac{d I_{\mathrm{pv}}}{d V_{\mathrm{pv}}}=0 .
$$

This leads to

$$
\frac{d I_{\mathrm{pv}}}{d V_{\mathrm{pv}}} \cong \frac{\Delta I_{\mathrm{pv}}}{\Delta V_{\mathrm{pv}}}=-\frac{I_{\mathrm{MPP}}}{V_{\mathrm{MPP}}} .
$$

Therefore, by evaluating the derivative, one can test whether the PV generator is operating at near MPP or far away from it:

$$
\left\{\begin{array}{l}
\frac{d P_{\mathrm{pv}}}{d V_{\mathrm{pv}}}=0 \\
\frac{d P_{\mathrm{pv}}}{d V_{\mathrm{pv}}}>0 \\
\frac{d P_{\mathrm{pv}}}{d V_{\mathrm{pv}}}<0
\end{array}\right\} \longrightarrow\left\{\begin{array}{c}
\frac{\Delta I_{\mathrm{pv}}}{\Delta V_{\mathrm{pv}}}=-\frac{I_{\mathrm{pv}}}{V_{\mathrm{pv}}}, \\
\frac{\Delta I_{\mathrm{pv}}}{\Delta V_{\mathrm{pv}}}>-\frac{I_{\mathrm{pv}}}{V_{\mathrm{pv}}}, \\
\frac{\Delta I_{\mathrm{pv}}}{\Delta V_{\mathrm{pv}}}<-\frac{I_{\mathrm{pv}}}{V_{\mathrm{pv}}} .
\end{array}\right\}
$$

Thus, the MPP can be reached by comparing the actual conductance $\left(I_{\mathrm{pv}} / V_{\mathrm{pv}}\right)$ to the incremental conductance $\left(I_{\mathrm{pv}} /\right.$ $\left.V_{\mathrm{pv}}\right)$ as shown in the flowchart given in Figure 6.

\subsection{Principle of the Modified MPPT Method Based on MPP-} Locus. The flowchart of this method is represented in Figure 7. Initially, after "Flag" is set as zero, the MPPT method uses the first condition to detect if there is an abrupt insolation variation. If there is no abrupt insolation variation, the conventional P\&O MPPT algorithm will be used to track the MPP as shown in Figure 8 [14]. Otherwise, three equations will be used to track the new MPP with a high convergence speed [14].

\subsection{Principle of the Proposed MPPT Method}

3.4.1. Characteristic of PV System with DC-DC Converter. A PV module consists of numbers of solar cells connected in series or parallel, and the total power generated is the sum of the power contributed by all of the individual solar cells. A DC-DC converter is connected in between the PV module and the load, as shown in Figure 9. Then, the MPPT controller is used to regulate the duty cycle of the DC-DC converter to ensure the load line always cuts through the $I-V$ curve at MPP [19].

The relationships of the voltage and current of the DCDC converter between the input and output sides are shown in

$$
\begin{aligned}
& V_{\mathrm{pv}}=\frac{V_{\mathrm{out}}}{M(d)}, \\
& I_{\mathrm{pv}}=I_{\text {out }} * M(d),
\end{aligned}
$$

where $M(d)$ can be written like

$$
M(d)=\frac{1}{1-d}
$$



FIgURE 9: Schematic diagram of the complete PV system.

Divide (4) by (5), it can be derived as

$$
R_{\mathrm{in}}=\frac{V_{\mathrm{pv}}}{I_{\mathrm{pv}}}=\frac{1}{M(d)^{2}} \times \frac{V_{\mathrm{out}}}{I_{\mathrm{out}}}=\frac{R_{\mathrm{out}}}{M(d)^{2}} .
$$

In a PV system, Equation (7) can be rewritten as

$$
R_{\mathrm{pv}}=R_{\mathrm{in}}=\frac{R_{\mathrm{out}}}{M(d)^{2}}=\frac{R_{\mathrm{load}}}{M(d)^{2}},
$$

where $R_{\mathrm{pv}}$ refers to the resistance seen by the PV string and $R_{\text {load }}$ refers to the load resistance, which can be calculated by substituting the duty cycle, voltage, and current of the PV module into (8).

$$
R_{\mathrm{load}}=\frac{1}{(1-d)^{2}} \times \frac{V_{\mathrm{pv}}}{I_{\mathrm{pv}}} .
$$

Equation (17) can be defined at the instant $(k)$ by

$$
R_{\text {load }}(k)=\frac{1}{(1-d(k))^{2}} \times \frac{V_{\mathrm{pv}}(k)}{I_{\mathrm{pv}}(k-1)} .
$$

The relationship of the duty cycle of the boost converter can be derived as

$$
d=1-\sqrt{\frac{R_{\mathrm{pv}}}{R_{\mathrm{load}}}} .
$$

3.4.2. The Improved MPPT Method. The improved method idea is based on the PV panel's $I-V$ characteristic under temperature variation as shown in Figures 10 and 11. As soon as the temperature increases from $25^{\circ} \mathrm{C}$ to $50^{\circ} \mathrm{C}$, the PV panel operating point (OP) moves from point $A$ $\left(V_{\mathrm{mpp} 1}, I_{\mathrm{mpp} 1}\right)\left(\mathrm{MPP}\right.$ of $\left.25^{\circ} \mathrm{C}\right)$ to point $B(V(k), I(k))$ along with the load line 1 , where the OP is too far away from point $E\left(V_{\mathrm{mpp} 2}, I_{\mathrm{mpp} 2}\right)$ (MPP of $50^{\circ} \mathrm{C}$ ) [22].

At this time, the PV panel OP is perturbed by the improved method to point $C(V(k), I(k-1))$ of the new load resistance (load line 2), where this latter is calculated by (10). In the next step, the new duty ratio is calculated by substituting the actual voltage $V(k), R_{\text {out }}(\mathrm{k})$, and the previous current 


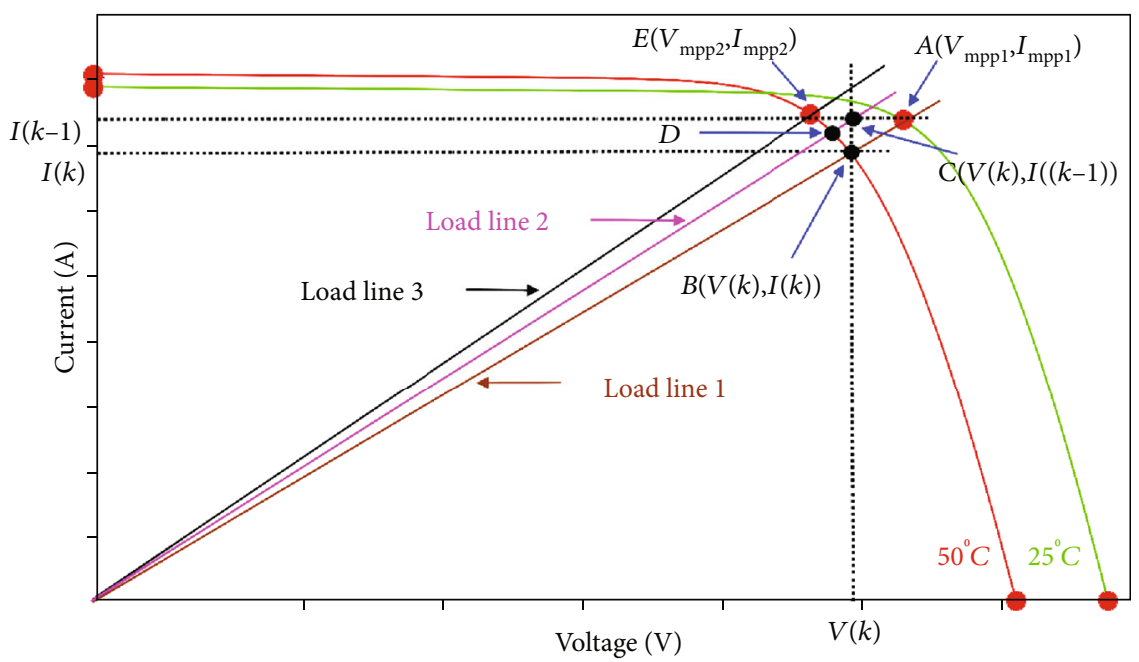

FIGURE 10: Operating point (OP) movement for the improved method under sudden increase of temperature.

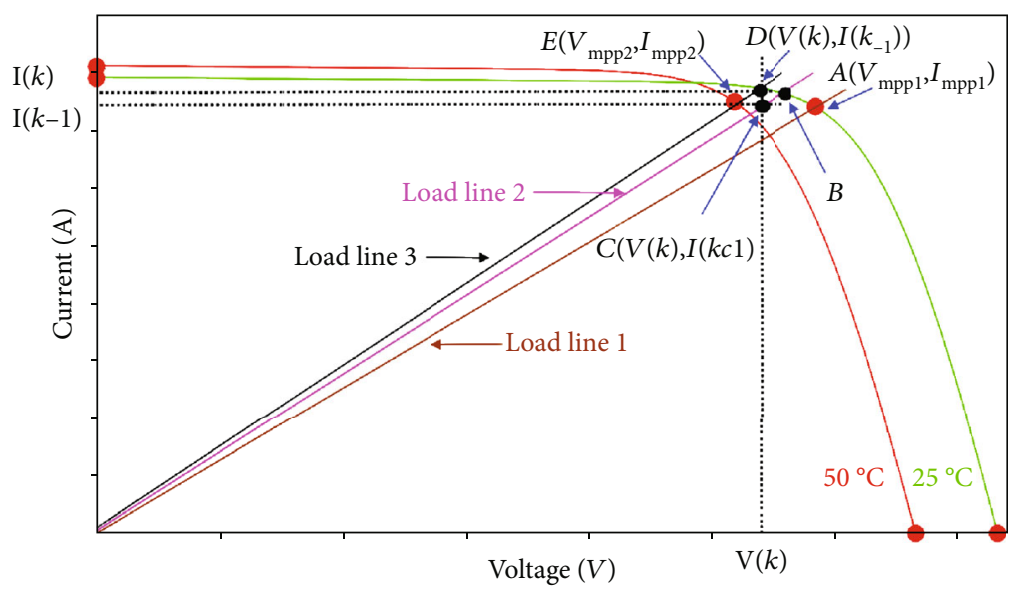

FIGURE 11: Operating point (OP) movement for the improved method under sudden decrease of temperature.

$I(k-1)$, in which it is approximated the previous maximum power point current $\left(I_{\mathrm{mpp} 1}\right)\left(\mathrm{MPP}\right.$ of $25^{\circ} \mathrm{C}$ ) into (12), and thus, the PV panel OP operates automatically at point $D$ of load line 2, as can be easily shown from Figure 12 [22].

$$
d(k+1)=1-\frac{\sqrt{V_{\mathrm{pv}}(k) / I_{\mathrm{pv}}(k-1)}}{\sqrt{R_{\operatorname{load}(k)}}} .
$$

Finally, only a few steps by a traditional MPPT method ( $\mathrm{P} \& \mathrm{O}, \mathrm{INC}, \mathrm{HC}$, etc.) are used to track the new maximum power point (MPP of $\left.50^{\circ} \mathrm{C}\right)$.

Like the previous case, when the temperature suddenly decreases, the PV panel OP moves from point $E$ $\left(V_{\mathrm{mpp} 2}, I_{\mathrm{mpp} 2}\right)\left(\mathrm{MPP}\right.$ of $\left.50^{\circ} \mathrm{C}\right)$ to point $D(V(k), I(k))$ along the load line 3. Then, the improved method perturbs the OP to point $C\left(V(k), I(k-1)\left(I_{\mathrm{mpp} 2}\right)\right)$ by calculating the resistance of the load line 2 using (10) and the new duty cycle using (12). Thus, the PV panel OP operates at point $B$, which is close to the new maximum power point (MPP of $25^{\circ} \mathrm{C}$ ) as shown in Figures 12 and 13, and finally, a few steps using a traditional MPPT method, the next MPP can be tracked [22].

Figure 14 illustrates the improved MPPT method's flowchart. Initially, the temperature situation is detected using the relation (13). If there is no temperature change, the $\mathrm{P} \& \mathrm{O}$ or INC MPPT algorithm will be used to track the MPP. Otherwise, (10) and (12) will be used to follow the new MPP with a high converging speed [22].

It can be concluded from $[2,30]$ and Figure 1 that the relations between power, voltage, and current change under temperature variation are met as shown below:

$$
\left.\begin{array}{l}
\Delta P \text { and } \Delta V<0, \Delta I<0 \text { Temperature increases } \\
\Delta P \text { and } \Delta V>0, \Delta I<0 \text { Temperature decreases }
\end{array}\right\} .
$$

\section{MPPT Tracking Efficiency}

The MPPT performance has become an interesting argument for manufacturers. However, there are no standards, which define how to evaluate MPPT performance, but some proposals are presented in the scientific literature [30]. 


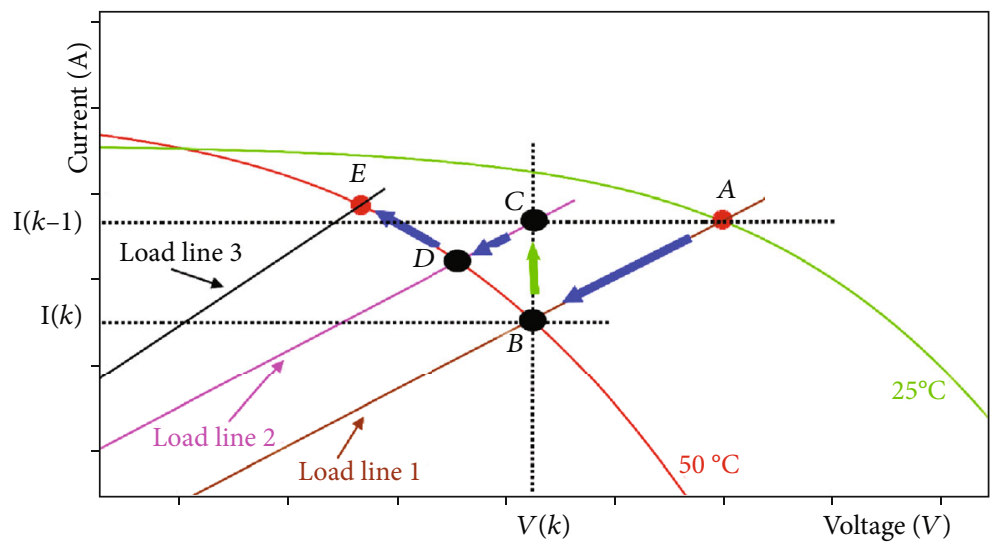

FIGURE 12: Operating point (OP) movement procedure under sudden increase of temperature.

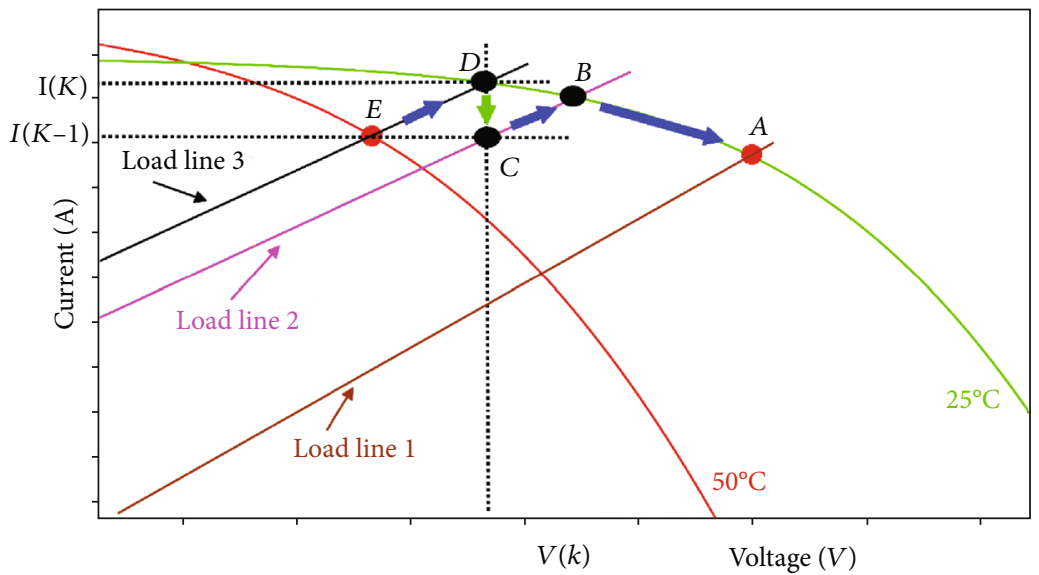

FIGURE 13: Operating point (OP) movement procedure under sudden decreasing of temperature.

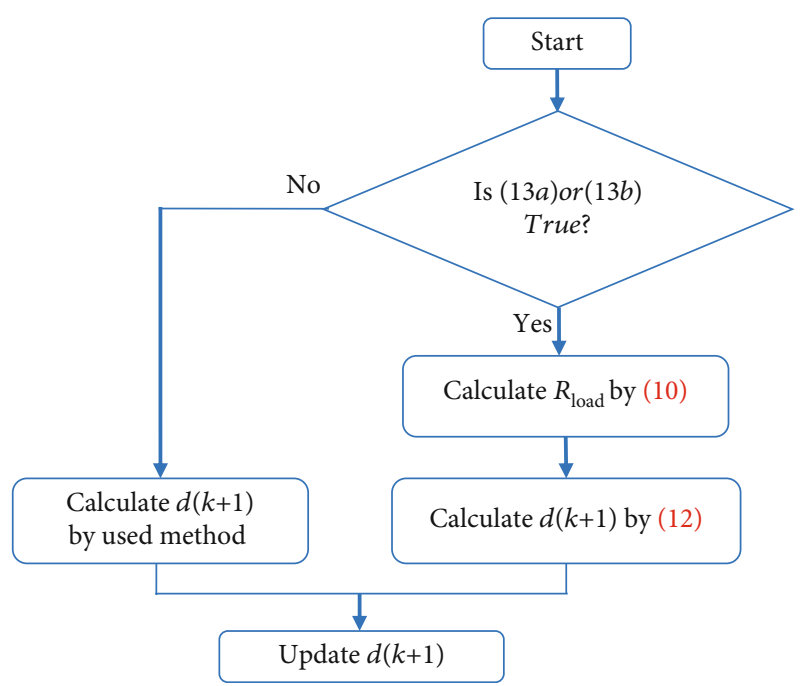

FIGURE 14: Flowchart of the proposed method.

The static MPPT efficiency is the ability of the MPPT algorithm to find and hold the MPP under steady-state conditions (normal solar radiation and cell temperature), while the dynamic MPPT efficiency is the capacity of an MPPT algo- rithm to survey the MPP under variable conditions [30]. The instantaneous MPPT efficiency can be calculated using

$$
\eta_{\mathrm{MPPT}}=\frac{P_{\mathrm{pv}}(k)}{P_{\mathrm{MPP}}(k)} \times 100 .
$$

The average MPPT tracking efficiency is given as

$$
\eta_{\mathrm{MPPT}(\mathrm{avg})}=\frac{\int P_{\mathrm{pv}}(k) \mathrm{dk}}{\int P_{\mathrm{MPP}}(k) \mathrm{dk}} \times 100,
$$

where

(i) $P_{\mathrm{pv}}(k)$ is the instantaneous extracted power using the MPPT approach

(ii) $P_{\mathrm{MPP}}(k)$ is the maximum theoretical power that can be extracted from the PV module

\section{Simulation Results}

In order to assess the performance of the suggested MPPT approach, a simulation comparison of the proposed MPPT approach with other MPPT methods, namely, P\&O, INC, 


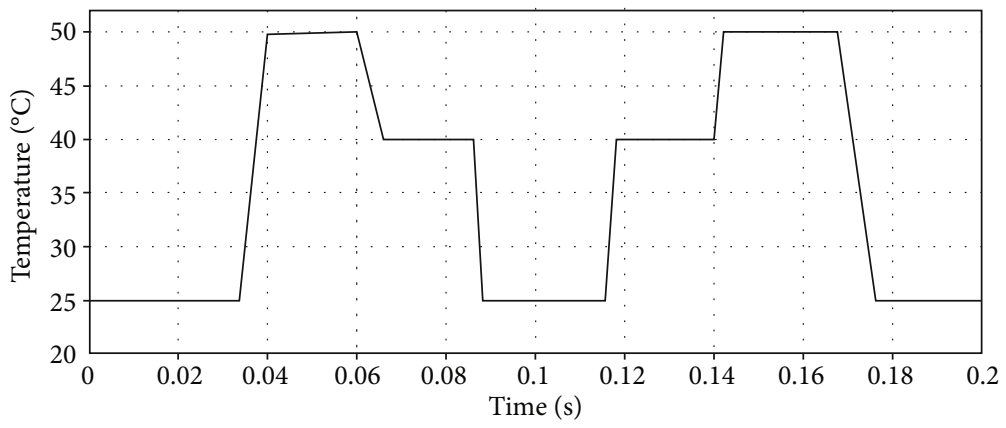

FIGURE 15: Scenario of temperature variation.

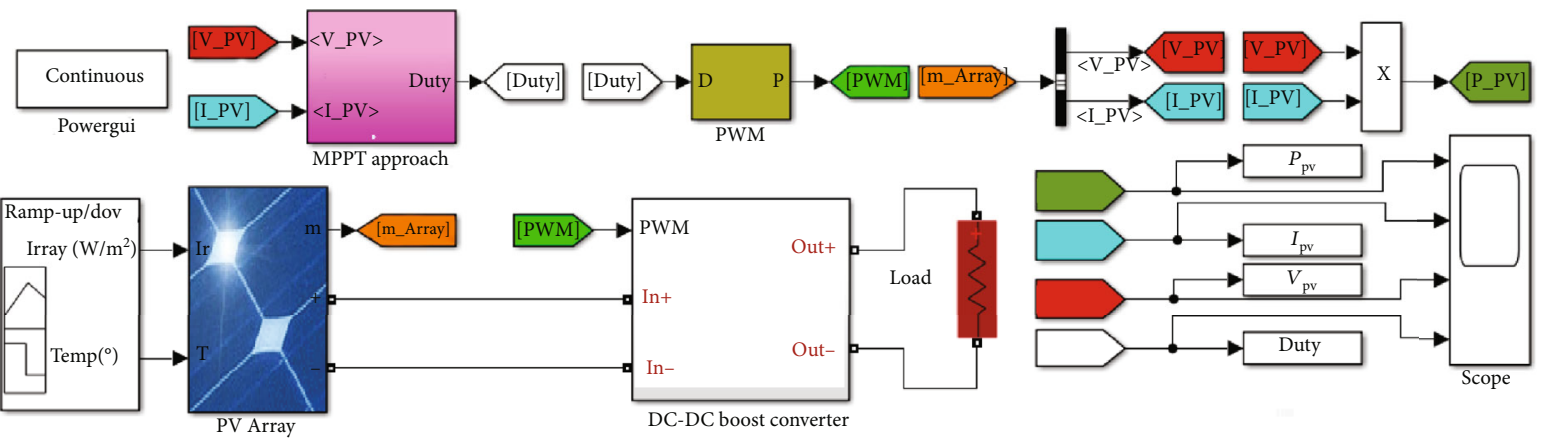

FIGURE 16: Schematic of the proposed PV system with MPPT algorithm.

and the modified MPP-Locus in [14], was carried out under the scenario of the temperature change as shown in Figure 15. The temperature rate was changed from $25^{\circ} \mathrm{C}$ to $50^{\circ} \mathrm{C}$ to $40^{\circ} \mathrm{C}$ than from $25^{\circ} \mathrm{C}$ to $40^{\circ} \mathrm{C}$ to $50^{\circ} \mathrm{C}$ to $25^{\circ} \mathrm{C}$; this scenario of temperature change was applied at constant irradiation: $1000 \mathrm{~W} / \mathrm{m}^{2}, 800 \mathrm{~W} / \mathrm{m}^{2}$, and $600 \mathrm{~W} / \mathrm{m}^{2}$. To verify the performance of the proposed method, a MATLAB/Simulink model of the overall PV system shown in Figure 16 was used, which contained the PV module, boost converter, resistive load, and an MPPT controller.

The 1Soltech 1STH-215-P is the PV panel used in this simulation, where its electrical specifications are shown in Table 1. The main specifications for the boost converter include $C_{\text {in }}=470 \mu \mathrm{F}, \quad C_{\text {out }}=47 \mu \mathrm{F}, \quad L=1 \mathrm{mH}$, and switching frequency $=25 \mathrm{kHz}$. The load resistance was set at $10 \Omega$.

5.1. Comparison of the $P \hookleftarrow O$ Method and the P\&O-IMP Method. The simulation results of the improved P\&O MPPT method compared with the conventional P\&O MPPT method under the scenario of temperature with constant irradiation are shown in Figure 17. The proposed method can successfully track the MPP with high performance and accuracy at the variation of temperature in different irradiation conditions (a) $1000 \mathrm{~W} / \mathrm{m}^{2}$, (b) $800 \mathrm{~W} / \mathrm{m}^{2}$, and (c) 600 $\mathrm{W} / \mathrm{m}^{2}$. Furthermore, thanks to its tracking mechanism, the tracking speed is significantly faster than the $\mathrm{P} \& \mathrm{O}$ algorithm, and it is noticeable that the improved MPPT tactic is able to reduce significantly the power losses especially at temperature variation. Moreover, it is clear from Figure 17 that by
TABLE 1: Parameter of the 1Soltech 1STH-215-P PV module at STC: temperature $=25^{\circ} \mathrm{C}$ and insolation $=1000 \quad \mathrm{~W} / \mathrm{m}^{2}$.

\begin{tabular}{lc}
\hline Parameters & Value \\
\hline Maximum power $\left(P_{\mathrm{MPP}}\right)$ & $213.15 \mathrm{~W}$ \\
Voltage at MPP $\left(V_{\mathrm{MPP}}\right)$ & $29 \mathrm{~V}$ \\
Current at MPP $\left(I_{\mathrm{MPP}}\right)$ & $7.35 \mathrm{~A}$ \\
Open-circuit voltage $\left(V_{\mathrm{oc}}\right)$ & $36.3 \mathrm{~V}$ \\
Short-circuit current $\left(I_{\mathrm{sc}}\right)$ & $7.84 \mathrm{~A}$ \\
Temperature coefficient of $V_{\mathrm{oc}}$ & $-0.36099\left(\% /{ }^{\circ} \mathrm{C}\right)$ \\
Temperature coefficient of $I_{\mathrm{sc}}$ & $0.102\left(\% /{ }^{\circ} \mathrm{C}\right)$ \\
\hline
\end{tabular}

using the improved P\&O MPPT method, we can reduce significantly the power loss in steady state and at temperature variation, especially with the increase of the temperature. There is a high amount of power loss, which is clear from the overshoot of power in Figure 17 when the traditional $\mathrm{P} \& \mathrm{O}$ is used. On the other hand, it can be seen that the good stability is at steady state of the PV module output power, voltage, current, and duty cycle of the boost converter in case of using the improved P\&O MPPT method, whereas no stability and fluctuation are present in the case of using the conventional P\&O MPPT algorithm.

Figure 18 presents the output power and voltage state under steady operation. Compared with the theoretical output value ( $P_{\text {mpp }}$ and $\left.V_{\text {mpp }}\right)$. It can be shown that the huge oscillations around the MPP are in a steady state when the conventional P\&O MPPT method is used, while the 

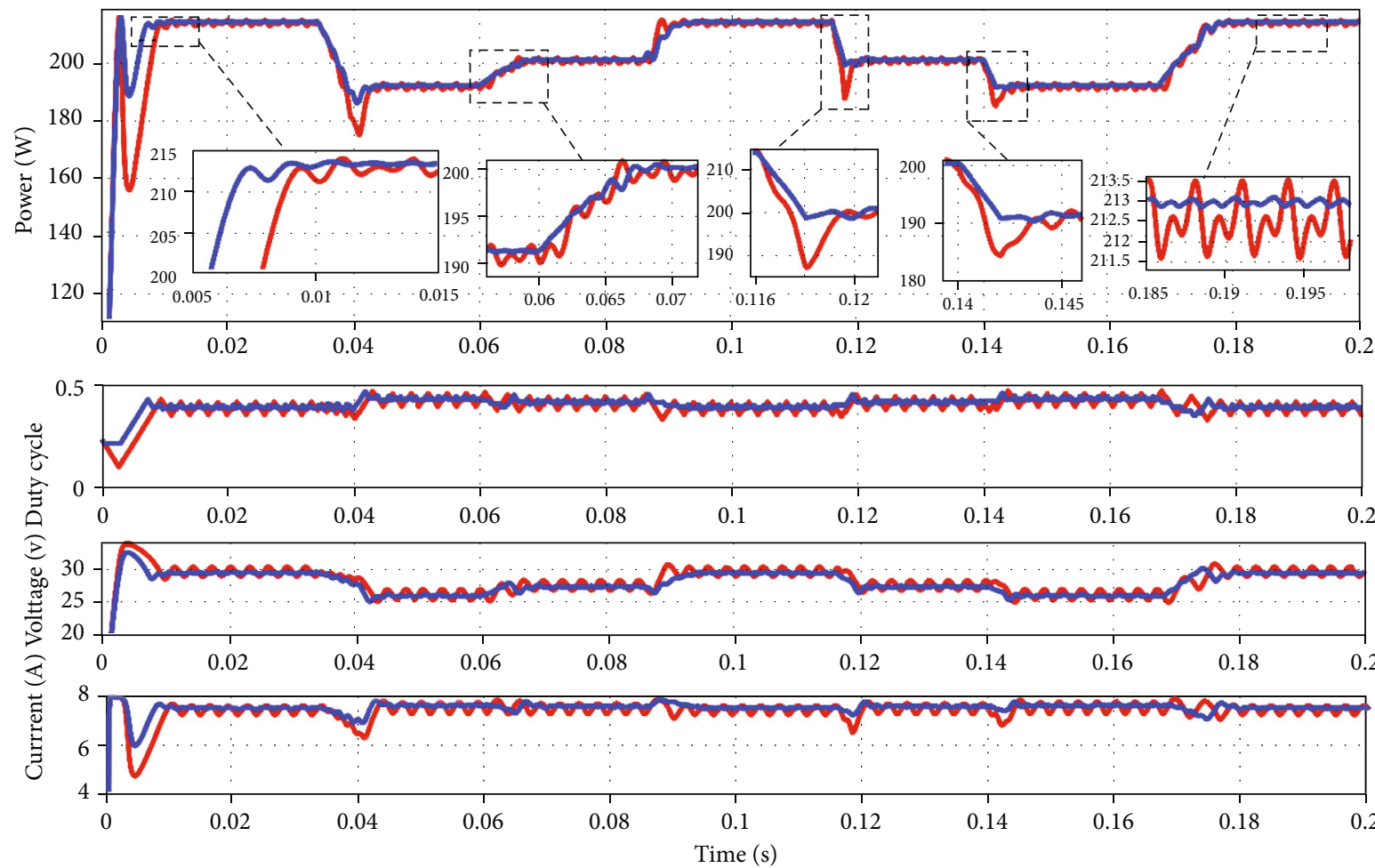

- $\mathrm{P} \& \mathrm{O}$

- P\&O-IMP

(a)
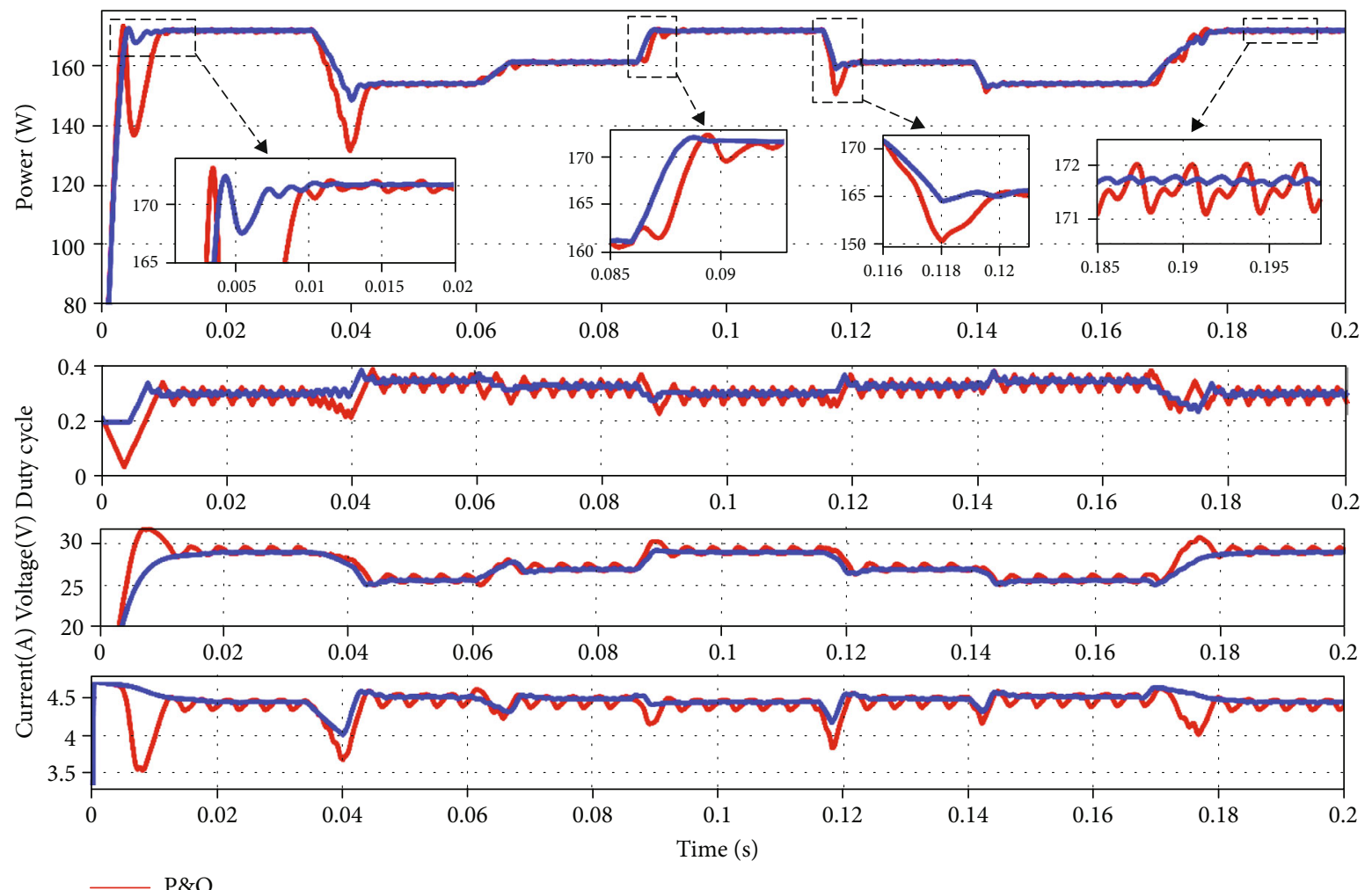

(b)

Figure 17: Continued. 

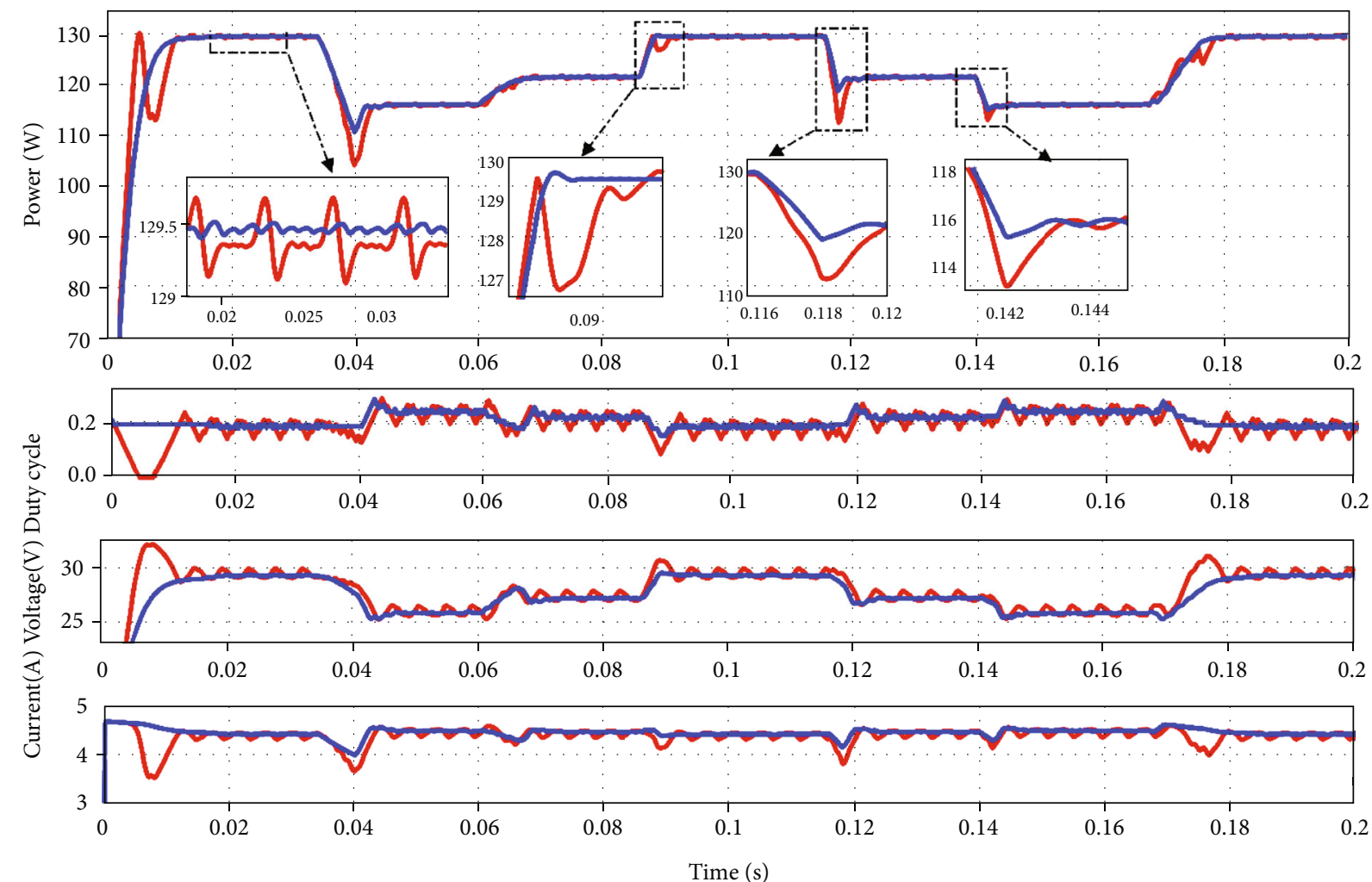

- P\&O

- P\&O-IMP

(c)

Figure 17: Simulation result comparison between the P\&O method and the P\&O-IMP method under the scenario of temperature variation with constant solar radiation: (a) $1000 \mathrm{~W} / \mathrm{m}^{2}$; (b) $800 \mathrm{~W} / \mathrm{m}^{2}$; (c) $600 \mathrm{~W} / \mathrm{m}^{2}$.

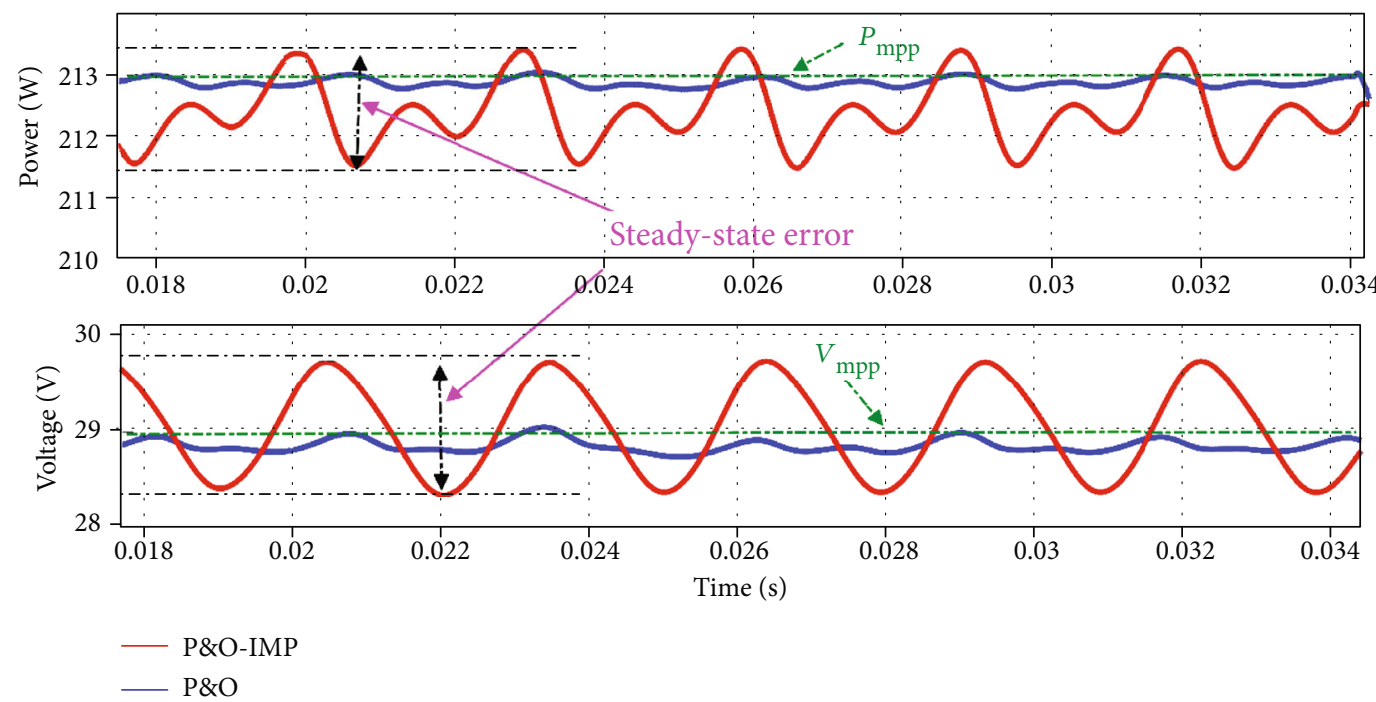

Figure 18: Comparison of the voltage and power in the steady state at $G=1000 \mathrm{~W} / \mathrm{m}^{2}$ and $T=25^{\circ} \mathrm{C}$.

improved P\&O MPPT strategy presents a neglected (slight) fluctuation around the MPP with better tracking of the theoretical output power, as well as a high power loss that is reduced. Furthermore, the improved $\mathrm{P} \& \mathrm{O}$ MPPT method is able to reduce the time response compared to the P\&O MPPT method to 2.06 milliseconds according to Figure 19.

To demonstrate the effectiveness and robustness of tracking of the proposed MPPT tactic, a calculation of the dynamic $\eta$ (dyn) and static $\eta$ (stat) efficiency is taken into 


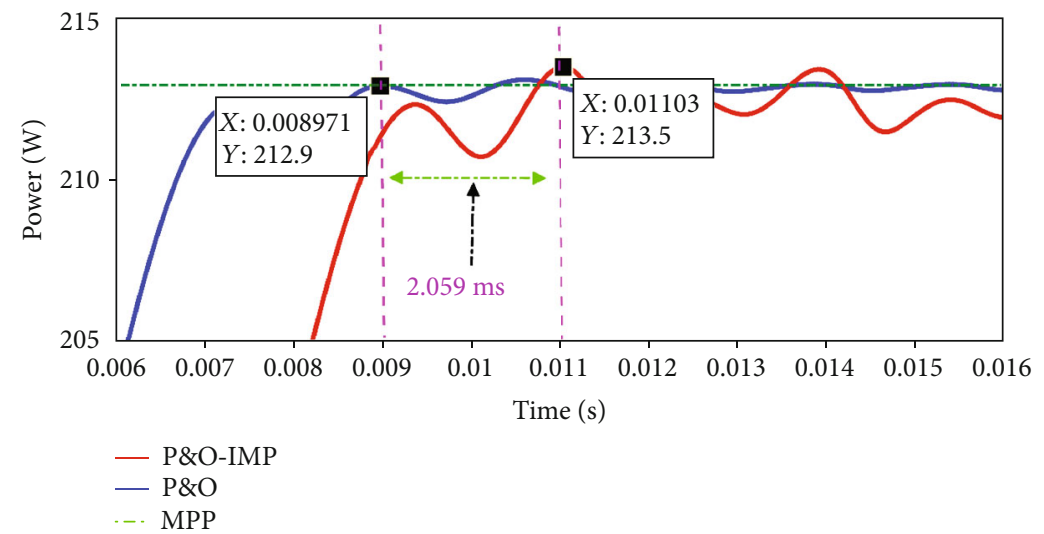

FIgURE 19: The response speed comparison for Figure 17(a).

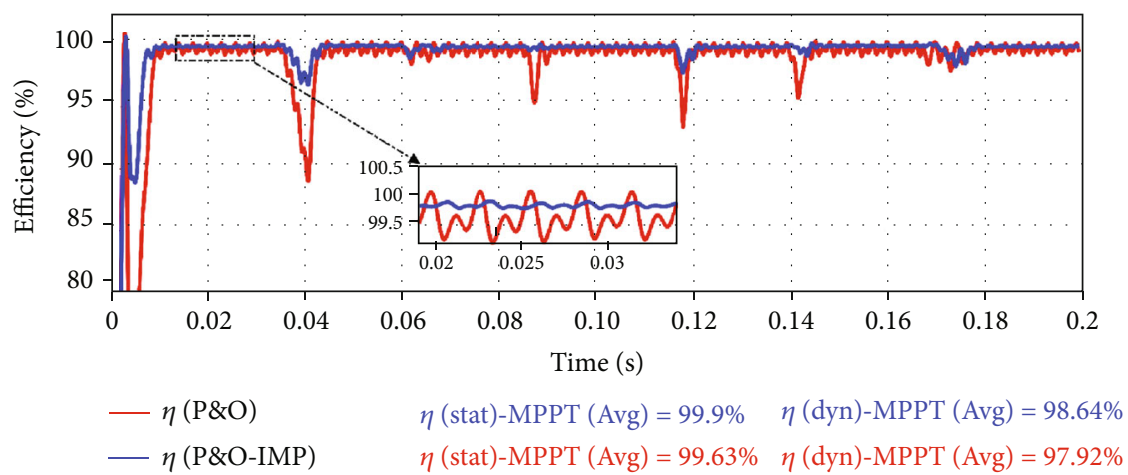

(a)
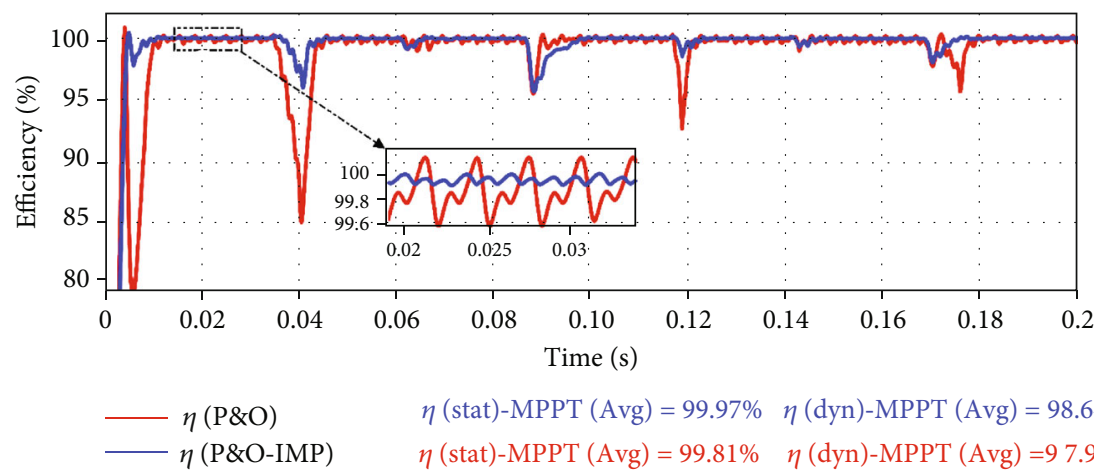

$\eta$ (stat)-MPPT $(\operatorname{Avg})=99.97 \% \quad \eta($ dyn $)-\mathrm{MPPT}(\operatorname{Avg})=98.64 \%$ $\eta($ stat $)-\mathrm{MPPT}(\operatorname{Avg})=99.81 \% \quad \eta($ dyn $)-\operatorname{MPPT}($ Avg $)=97.92 \%$

(b)

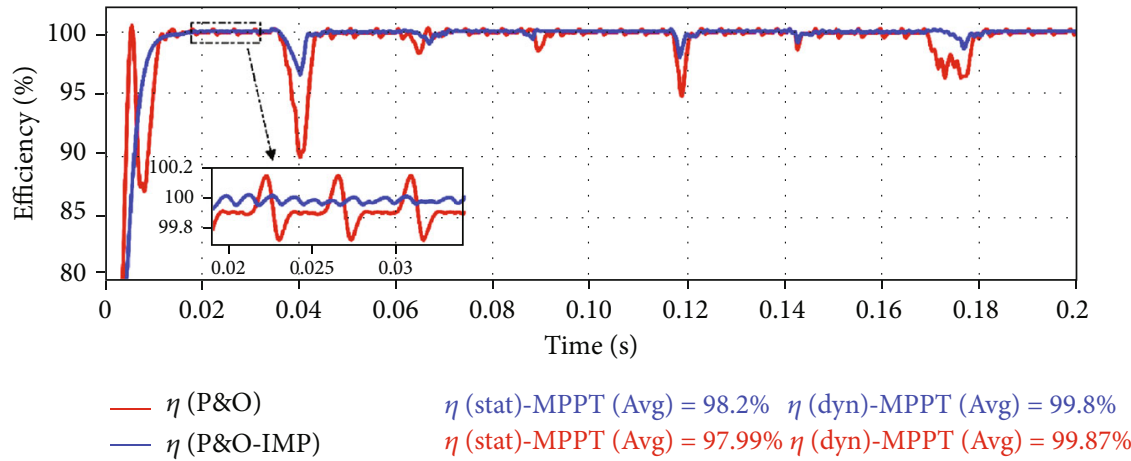

(c)

Figure 20: Efficiency profile comparison between the P\&O MPPT algorithm and the improved P\&O MPPT under the scenario of temperature variation with normal solar radiation (a) $1000 \mathrm{~W} / \mathrm{m}^{2}$, (b) $800 \mathrm{~W} / \mathrm{m}^{2}$, and (c) $600 \mathrm{~W} / \mathrm{m}^{2}$. 

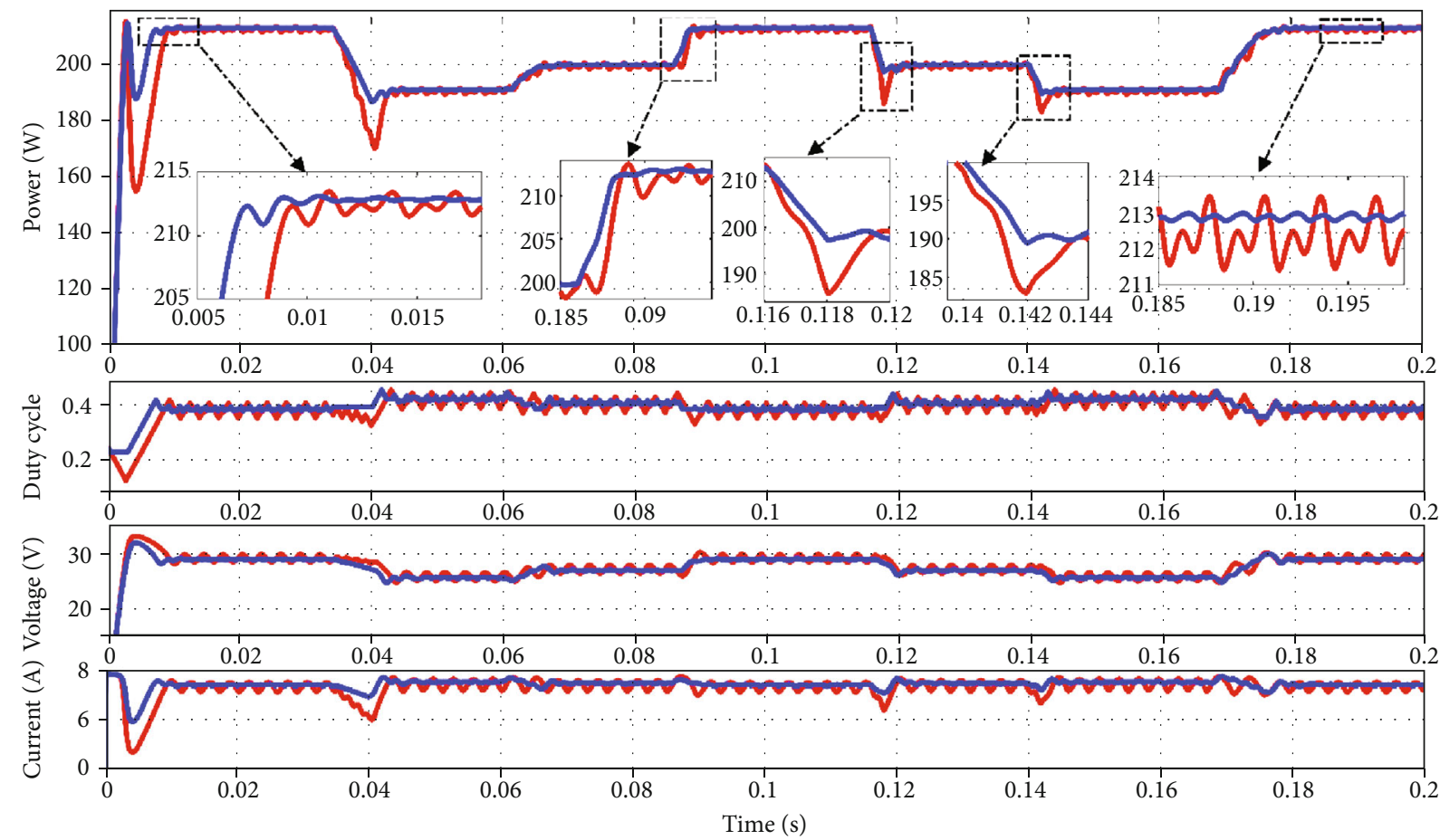

- INC

- INC-IMP

(a)
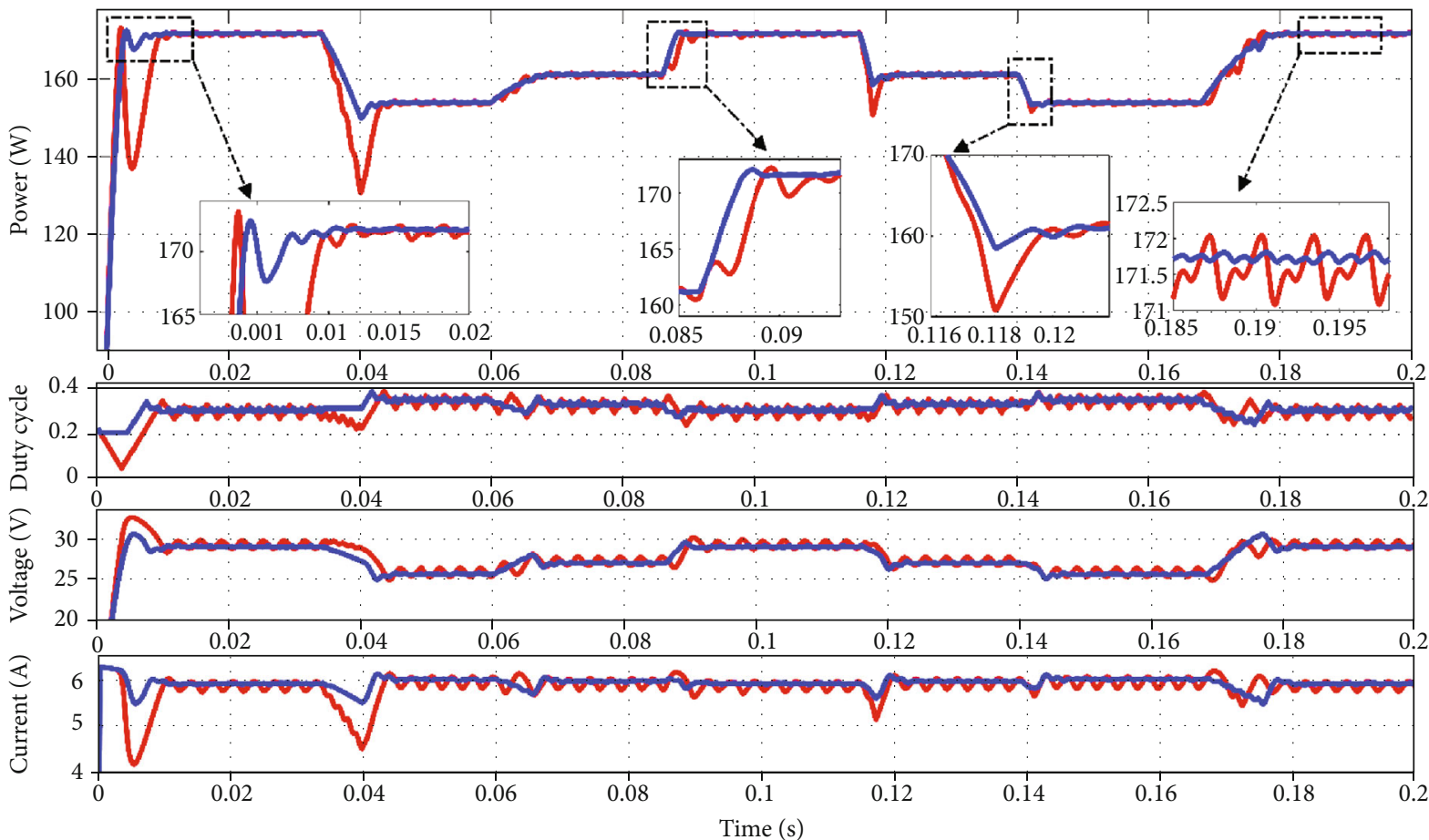

- INC

— INC-IMP

(b)

Figure 21: Continued. 


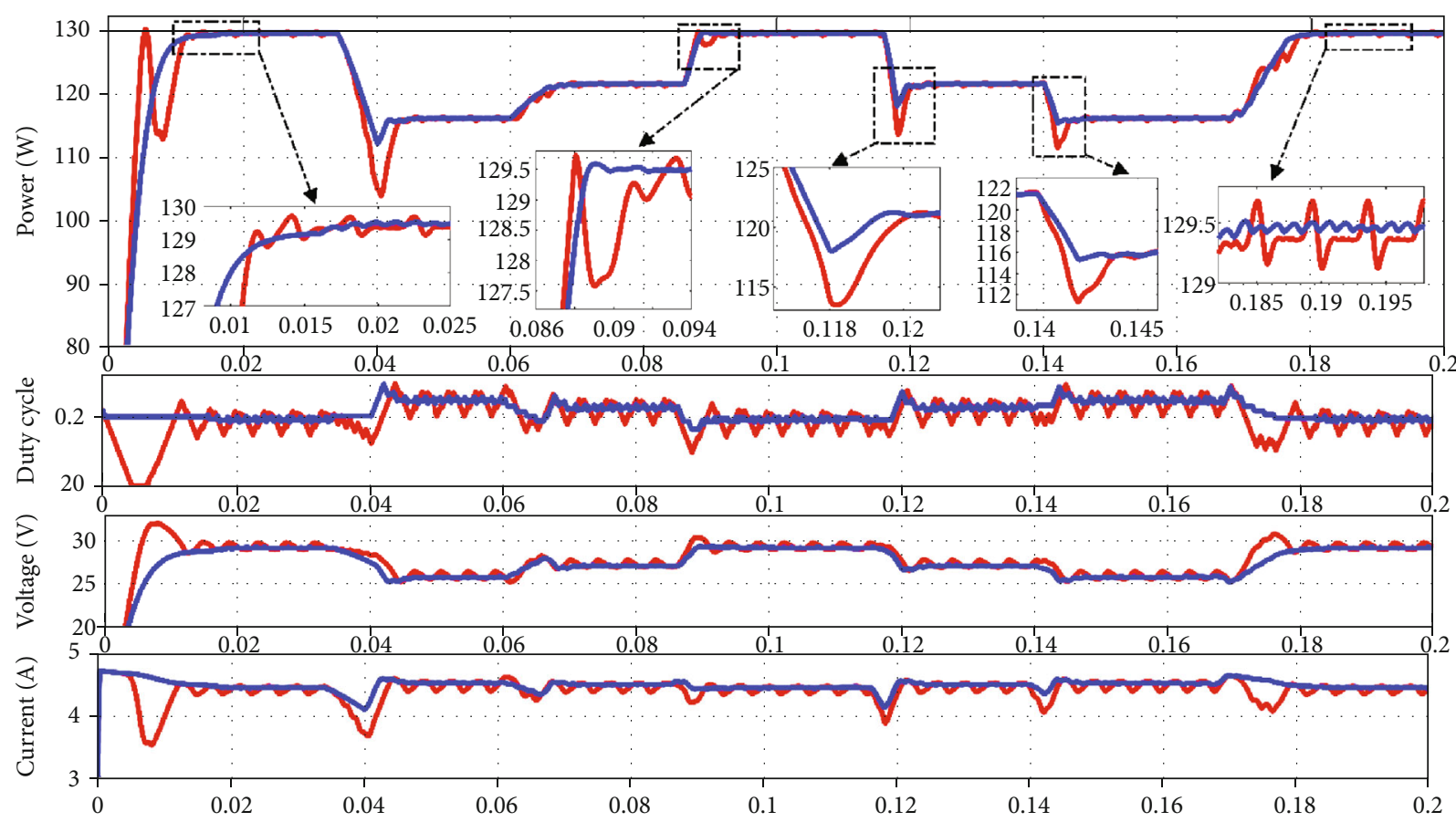

(c)

FIGURE 21: Simulation results from the comparison between the INC and INC-IMP methods under the scenario of temperature variation with constant solar irradiance: (a) $1000 \mathrm{~W} / \mathrm{m}^{2}$; (b) $800 \mathrm{~W} / \mathrm{m}^{2}$; (c) $600 \mathrm{~W} / \mathrm{m}^{2}$.


- INC-IMP

- INC

Figure 22: Comparison of the voltage and power in the steady state at $G=800 \mathrm{~W} / \mathrm{m}^{2}$ and $T=25^{\circ} \mathrm{C}$.

consideration. Figure 20 presents the efficiency profile comparison between the P\&O MPPT algorithm and improved $\mathrm{P} \& \mathrm{O}$ MPPT algorithm under the scenario (condition) of temperature variation with normal solar radiation: (a) 1000 $\mathrm{W} / \mathrm{m}^{2}$, (b) $800 \mathrm{~W} / \mathrm{m}^{2}$, and (c) $600 \mathrm{~W} / \mathrm{m}^{2}$.

From Figure 20, we can observe the huge dropping of the efficiency when the temperature changes in the case of using the traditional P\&O MPPT algorithm, where the instantaneous efficiency drops down to $86 \%$. Furthermore, in the steady-state condition, the instantaneous efficiency varies in the range of $99.2 \%$ to $100.2 \%$ due to the oscillations; as a result, the average of dynamic and static effi- ciency is $97.92 \%$ and $99.63 \%$, respectively, at $1000 \mathrm{~W} / \mathrm{m}^{2}$ of solar radiation, $97.92 \%$ and $99.81 \%$ at $800 \mathrm{~W} / \mathrm{m}^{2}$, and $97.99 \%$ and $99.87 \%$ at $600 \mathrm{~W} / \mathrm{m}^{2}$, whereas the improved P\&O MPPT method shows the best efficiency in the variation of temperature, which is above 95\% during the whole test time, and in the steady-state operation, the instantaneous efficiency is significantly stable and varies in the range of $99.9 \%$ to $99.99 \%$. As shown in Figure 20, the average dynamic $\eta$ (dyn) and static $\eta$ (stat) efficiency is $98.64 \%$ and $99.9 \%$, respectively, at $1000 \mathrm{~W} / \mathrm{m}^{2}$ of solar radiation, $98.64 \%$ and $99.97 \%$ at $800 \mathrm{~W} / \mathrm{m}^{2}$, and $98.2 \%$ and $99.98 \%$ at $600 \mathrm{~W} / \mathrm{m}^{2}$. 


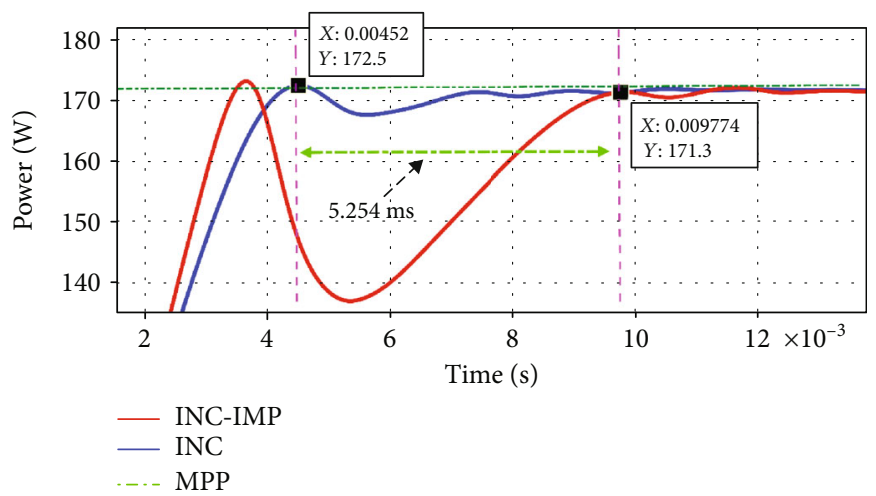

FIGURE 23: The response speed comparison for Figure 21(b).

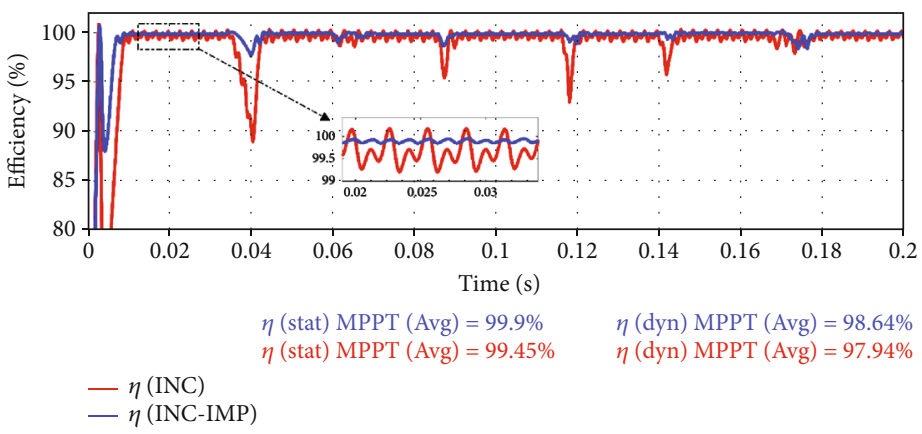

(a)

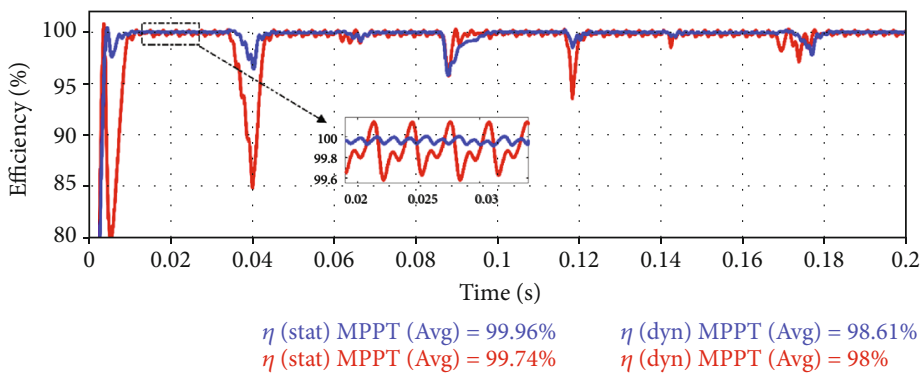

$\eta(\mathrm{INC})$
$-\eta(\mathrm{INC}-\mathrm{IMP})$

(b)

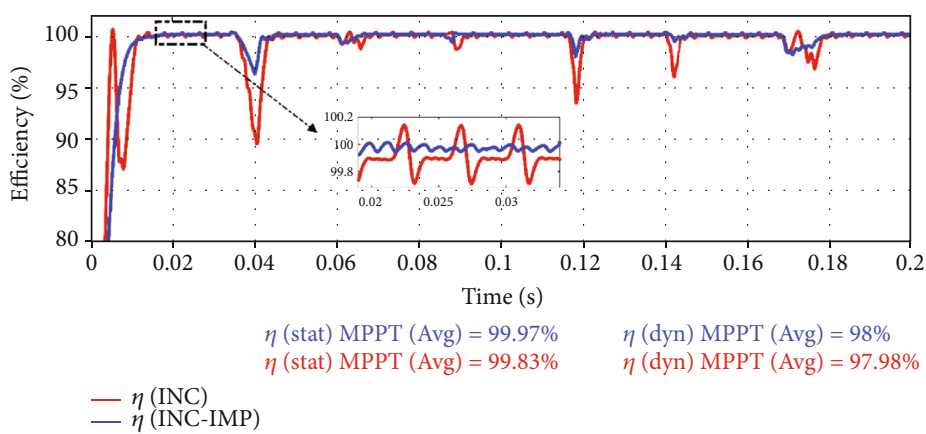

(c)

FIgURE 24: Efficiency profile comparison between the conventional INC and improved INC MPPT methods under the scenario of temperature variation with normal solar radiation (a) $1000 \mathrm{~W} / \mathrm{m}^{2}$, (b) $800 \mathrm{~W} / \mathrm{m}^{2}$, and (c) $600 \mathrm{~W} / \mathrm{m}^{2}$. 


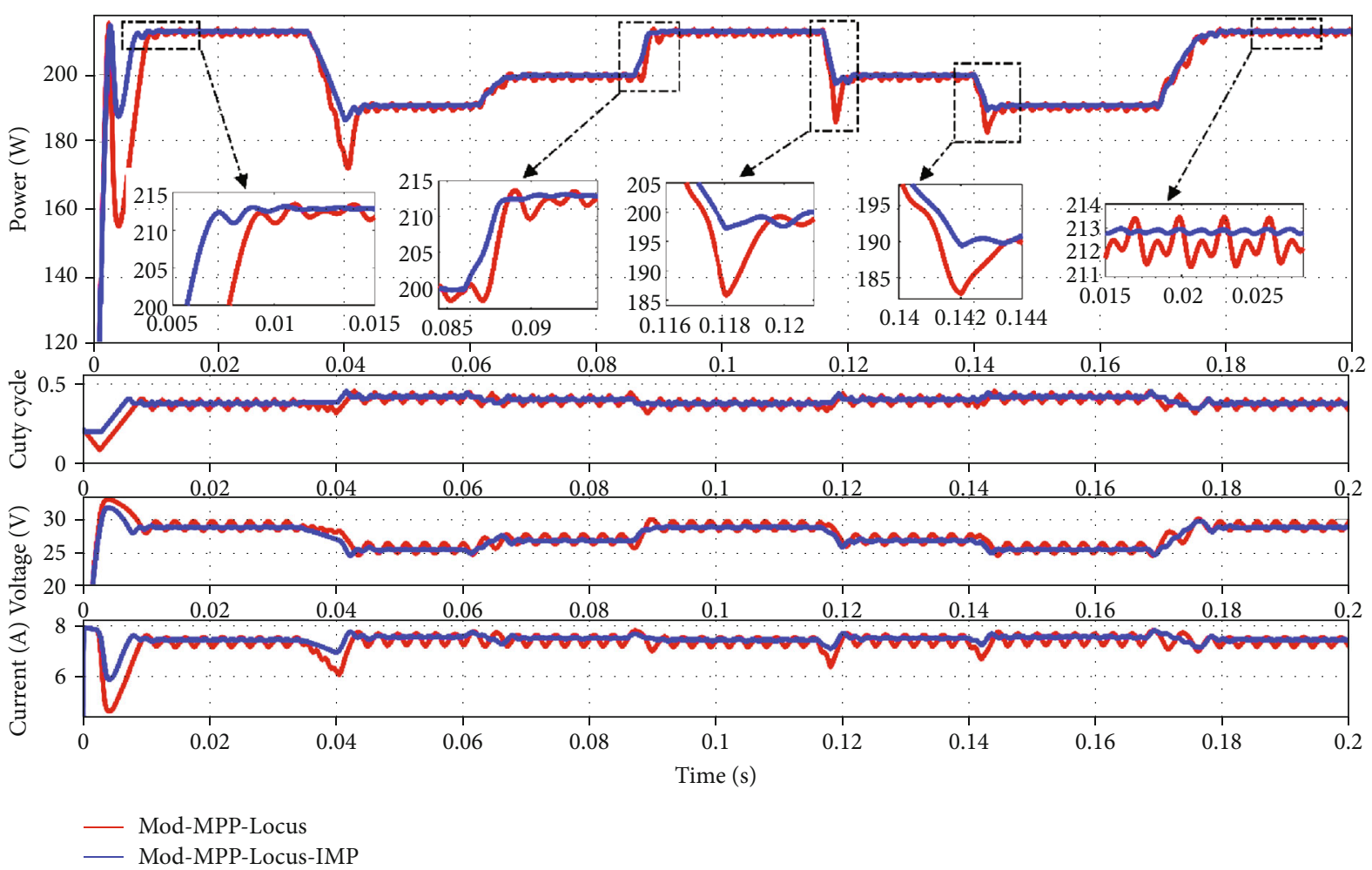

(a)
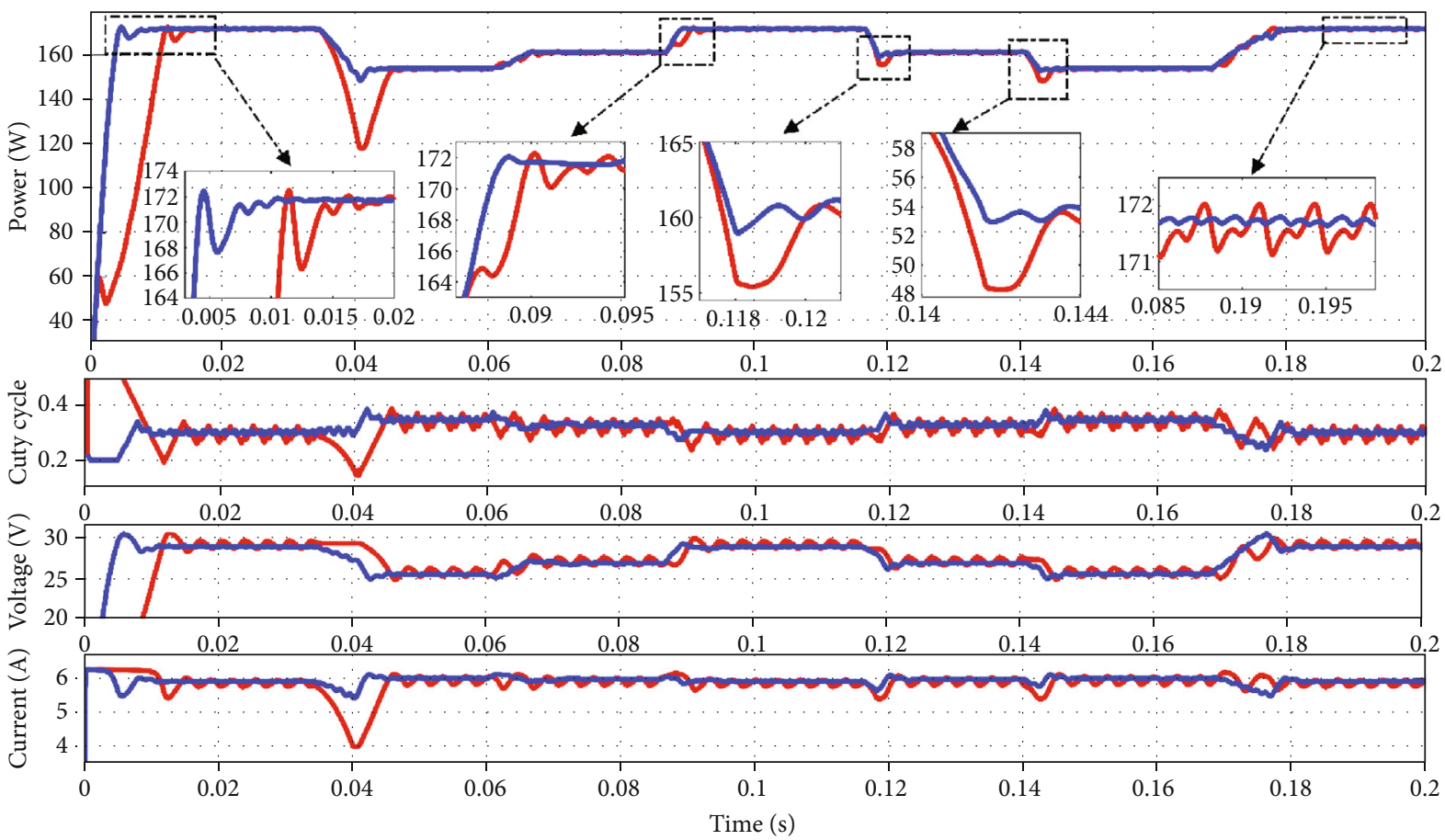

- Mod-MPP-Locus

— Mod-MPP-Locus-IMP

(b)

Figure 25: Continued. 

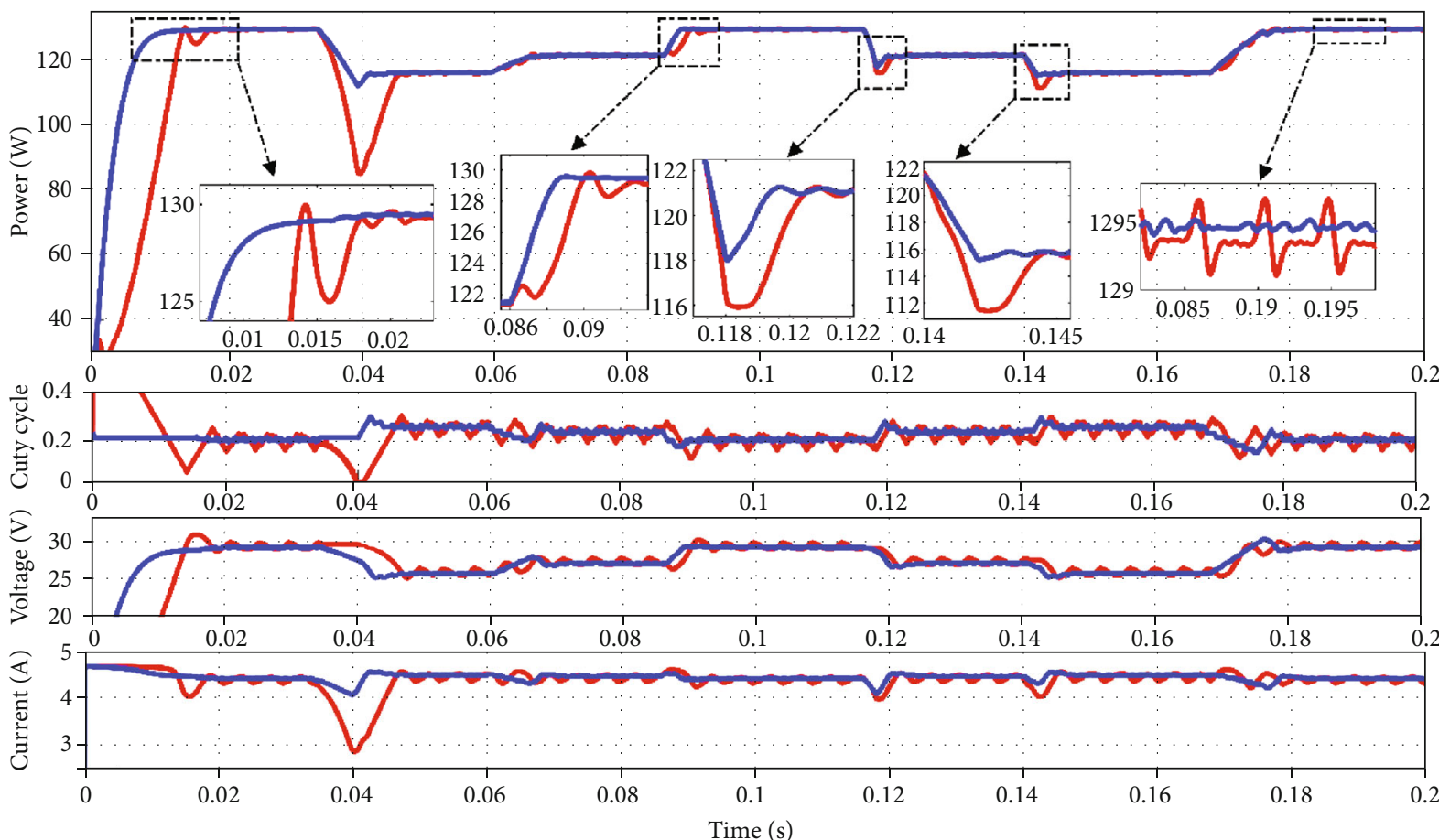

- Mod-MPP-Locus

- Mod-MPP-Locus-IMP

(c)

FIGURE 25: Simulation results from the comparison between the modified and the improved modified MPP-Locus-IMP MPPT methods under the scenario of temperature variation with constant solar irradiance: (a) $1000 \mathrm{~W} / \mathrm{m}^{2}$; (b) $800 \mathrm{~W} / \mathrm{m}^{2}$; (c) $600 \mathrm{~W} / \mathrm{m}^{2}$.

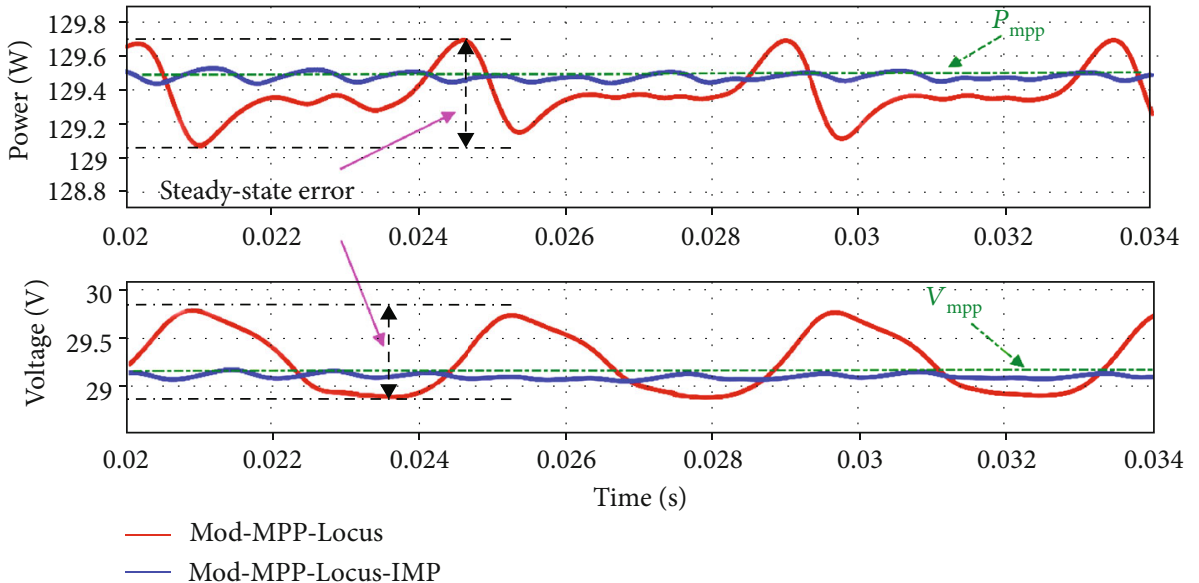

Figure 26: Comparison of the voltage and power in the steady state at $G=600 \mathrm{~W} / \mathrm{m}^{2}$ and $T=25^{\circ} \mathrm{C}$.

5.2. Comparison of the INC Method and the INC-IMP Method. Figure 21 shows the simulation result for the comparison of the INC method and the improved method INCIMP under the scenario of temperature variation with a constant solar radiance: (a) $1000 \mathrm{~W} / \mathrm{m}^{2}$, (b) $800 \mathrm{~W} / \mathrm{m}^{2}$, and (c) $600 \mathrm{~W} / \mathrm{m}^{2}$, where it is clear that the good performance of the improved INC MPPT tactic provides the MPP with high accuracy and limits the power losses at temperature variation.

From the simulation results, the improved INC MPPT method provides a good tracking of the MPP during the time simulation, especially when the temperature changes, where it can minimize significantly the power loss. On the other hand, Figure 22 presents the comparison of the voltage and power in the steady-state operation where better tracking performance for the improved INC MPPT method with a few steady-state errors around the MPP is manifested. In addition, from Figure 23, the improved INC MPPT tactic presents a high response speed and a better tracking accuracy, where it can reduce the time response to 5.25 milliseconds. 


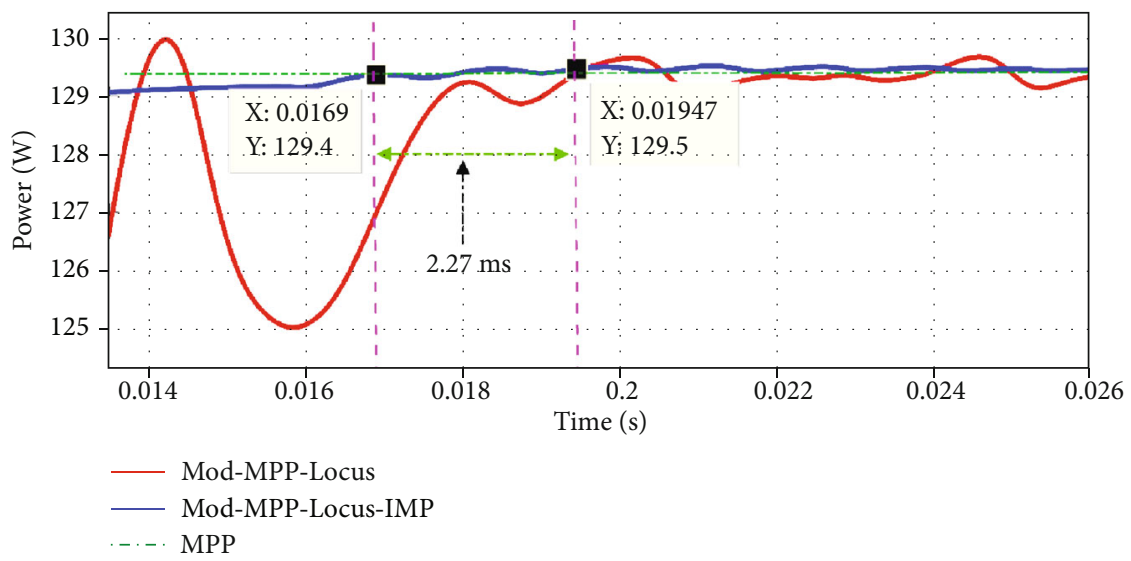

FIGURE 27: The response speed comparison for Figure 25(c).

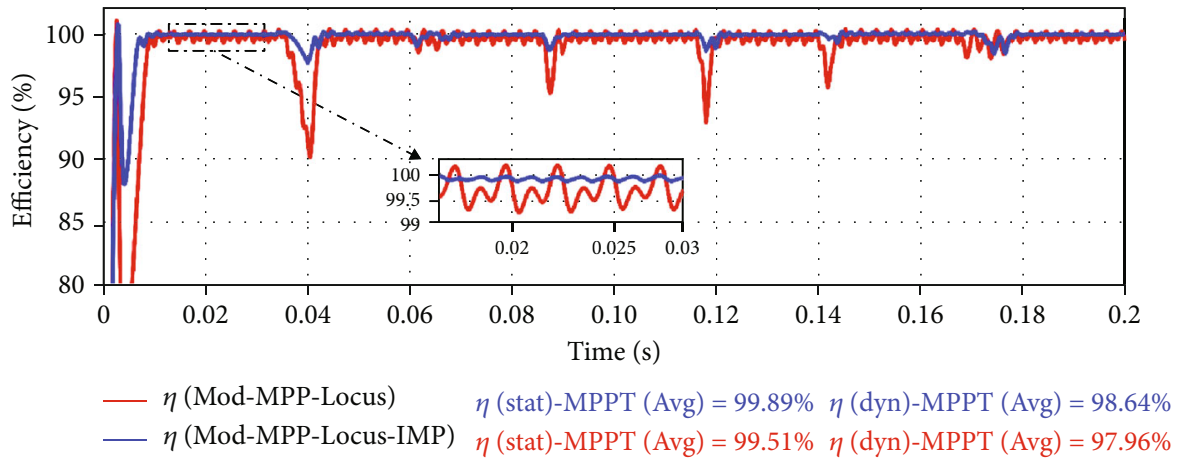

(a)

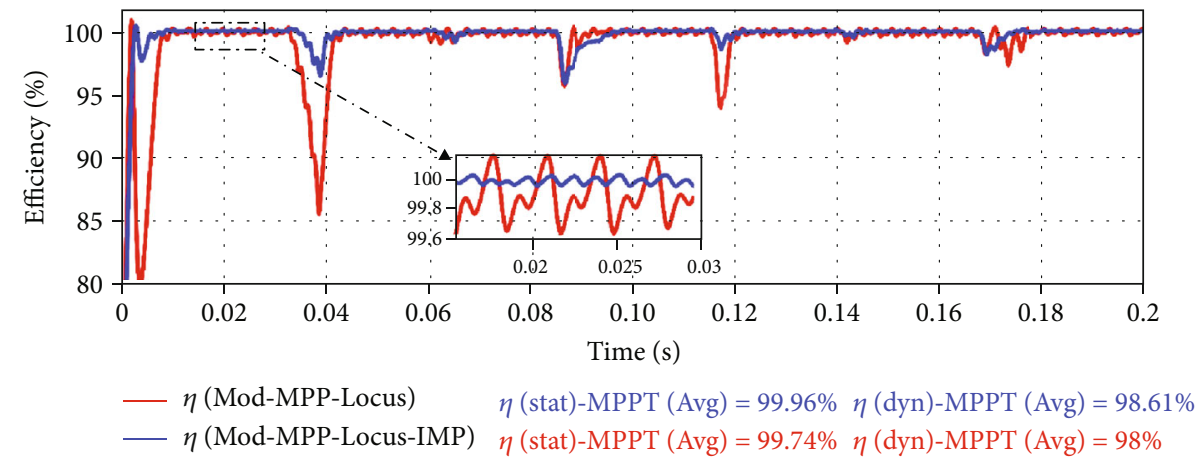

(b)

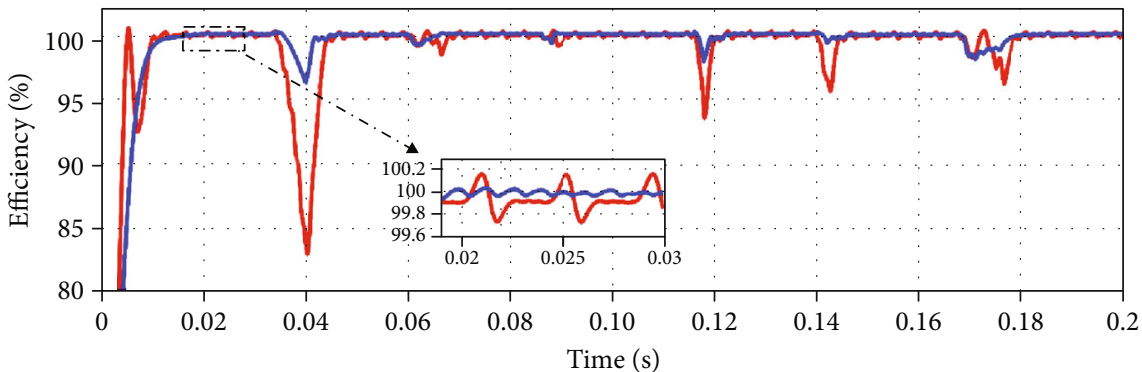

$$
\begin{aligned}
& \eta \text { - } \quad \text { (Mod-MPP-Locus) } \quad \eta \text { (stat)-MPPT (Avg) }=99.98 \% \quad \eta \text { (dyn)-MPPT (Avg) }=98 \% \\
& -\eta \text { (Mod-MPP-Locus-IMP) } \quad \eta \text { (stat)-MPPT (Avg) }=99.83 \% \quad \eta(\text { dyn }) \text {-MPPT (Avg) }=97.93 \%
\end{aligned}
$$

(c)

Figure 28: Efficiency profile comparison between the Mod-MPP-Locus MPPT method and the improved Mod-MPP-Locus MPPT method under the scenario of temperature variation with a normal solar radiation (a) $1000 \mathrm{~W} / \mathrm{m}^{2}$, (b) $800 \mathrm{~W} / \mathrm{m}^{2}$, and (c) $600 \mathrm{~W} / \mathrm{m}^{2}$. 
TABLE 2: Simulation result performance from the comparison of different MPPT control methods.

\begin{tabular}{lcccccc}
\hline Algorithm & P\&O & P\&O-IMP & INC & INC-IMP & Mod-Locus MPPT & Mod-Locus MPPT-IMP \\
\hline Tracking speed & Medium & Faster & Medium & Faster & Slow & Faster \\
Steady-state oscillation & Large & Small & Medium & Small & Medium & Small \\
Accuracy/efficiency & Low & High & Medium & High & Medium & High \\
Dynamic efficiency range (\%) & $97.92-97.99$ & $98.2-98.64$ & $97.94-98$ & $98-98.64$ & $97.93-98$ & $98-98.64$ \\
Static efficiency range (\%) & $99.63-99.87$ & $99.9-99.98$ & $99.45-99.83$ & $99.9-99.7$ & $99.51-99.83$ & $99.89-99.98$ \\
Time response (ms) & 11.03 & 8.97 & 9.77 & 4.52 & 19.47 & 16.9 \\
Power steady-state error (W) & 2 & Neglected & 1 & Neglected & 0.6 & Neglected \\
Voltage steady-state error (V) & 1.5 & Neglected & 1 & Neglected & 1 & Neglected \\
Power overshoot & High & Insignificant & High & Insignificant & High & Insignificant \\
\hline
\end{tabular}

Figure 24 presents the efficiency profile comparison between the conventional INC and the improved INC MPPT algorithms under the scenario of temperature change with constant solar radiation: (a) $1000 \mathrm{~W} / \mathrm{m}^{2}$, (b) $800 \mathrm{~W} / \mathrm{m}^{2}$, and (c) $600 \mathrm{~W} / \mathrm{m}^{2}$. From Figure 24 , we can observe the best tracking efficiency of the improved INC MPPT method during the scenario of temperature variation and under different solar radiations, whereas the tracking efficiency of the INC MPPT algorithm is obviously affected by the temperature change, which drops to as low as $85 \%$. In the case of the improved INC MPPT method, the tracking efficiency is maintained around $99.9 \%$ for most of the time as shown in zoomed portions of Figure 24, while the tracking efficiency is perturbed and shows a high fluctuation in the case of using the INC MPPT method. Furthermore, the average dynamic $\eta$ (dyn) and static $\eta$ (stat) efficiency of the INC MPPT method varies from $97.94 \%$ to $98 \%$ and from $99.45 \%$ to $99.83 \%$, respectively. On the other hand, the average dynamic $\eta$ (dyn) and static $\eta$ (stat) efficiency varied from $98 \%$ to $98.64 \%$ and from $99.9 \%$ to $99.97 \%$, respectively, in the case of using the improved INC MPPT method.

5.3. Comparison of the Modified MPP-Locus Method and the Modified MPP-Locus-IMP Method. The simulation results presented in Figure 25 show the comparison of the ModMPP-Locus method and the improved Mod-MPP-Locus MPPT method under the scenario of temperature change with different constant solar radiations $1000 \mathrm{~W} / \mathrm{m}^{2}, 800$ $\mathrm{W} / \mathrm{m}^{2}$, and $600 \mathrm{~W} / \mathrm{m}^{2}$, respectively. The results show clearly the high tracking performance of the improved Mod-MPPLocus MPPT method compared with the Mod-MPP-Locus MPPT method, which losses the tracking direction due to temperature change. Furthermore, the improved ModMPP-Locus MPPT method tracks the MPP at any temperature level easily with a neglected oscillation around the MPP and the MPP is accurately reached in case of the fast change of temperature, whereas the Mod-MPP-Locus MPPT method presents a high power loss due to fast temperature change, which is clearly observed in Figure 25 by the huge overshoots.

Figure 26 presents the PV output power and voltage of the Mod-MPP-Locus MPPT method and the improved Mod-MPP-Locus MPPT method under steady-state operation, compared with the theoretical output value $\left(P_{\text {mpp }}\right.$ and
$\left.V_{\text {mpp }}\right)$. It is clear from Figure 26 that there exists a large oscillation around the theoretical output value of the power and voltage in case of using the Mod-MPP-Locus strategy, while the improved Mod-MPP-Locus strategy is able to track the theoretical output value of the power and voltage with neglected oscillations. In addition, the response time in case of using the improved Mod-MPP-Locus is reduced to 2.57 milliseconds as reported in Figure 27.

The simulation results presented in Figure 28 show the efficiency profile comparison between the Mod-MPP-Locus MPPT method and the improved Mod-MPP-Locus MPPT method under the scenario of temperature variation with a normal solar radiation (a) $1000 \mathrm{~W} / \mathrm{m}^{2}$, (b) $800 \mathrm{~W} / \mathrm{m}^{2}$, and (c) $600 \mathrm{~W} / \mathrm{m}^{2}$.

Due to the repeated loss of the tracking direction, we can observe from Figure 28 the huge dropping of the efficiency at temperature changing in case of using the Mod-MPP-Locus MPPT method, where the instantaneous efficiency goes as low as $83 \%$. Moreover, in the steady-state condition, the instantaneous efficiency varies in the range of $99.2 \%$ to $100.2 \%$ because of the oscillations; as a result, the average of dynamic and static efficiency varies under different solar radiations from $97.93 \%$ to $98 \%$ and from $99.51 \%$ to $99.83 \%$, respectively. On the other hand, the improved Mod-MPPLocus MPPT method exhibits excellent tracking efficiency over the whole test processing, especially in the fast variation of temperature, where its instantaneous efficiency is continuously above 95\% under all conditions. Furthermore, in steady-state operation, the instantaneous efficiency is significantly stable and varies in the range of $99.9 \%$ to $99.99 \%$, and the average of dynamic $\eta$ (dyn) and static $\eta$ (stat) efficiency under different irradiations is $98.64 \%$ and $99.89 \%$ at 1000 $\mathrm{W} / \mathrm{m}^{2}, 98.61 \%$ and $99.96 \%$ at $800 \mathrm{~W} / \mathrm{m}^{2}$, and $98 \%$ and $99.98 \%$ at $600 \mathrm{~W} / \mathrm{m}^{2}$, respectively.

Finally, Table 2 presents the recapitulation of all simulation results, which validates the effectiveness and feasibility of the proposed MPPT tactic.

\section{Conclusion}

This work proposes an improved MPPT algorithm, which can be easily added to other existing MPPT algorithms to enhance their tracking performance, especially under temperature variation. A comparative study with three MPPT 
algorithms, namely, perturb and observe ( $\mathrm{P} \& \mathrm{O})$, incremental conductance (INC), and modified MPP-Locus, has been done under MATLAB/Simulink software. The simulation results demonstrate good contributions on the dynamic response to the temperature variation, as well as on the steady-state performance, where there is a significant improvement in the response time, minimization of oscillation size around the MPP, and the tracking efficiency; as a result, a high amount of power loss can be significantly reduced. Furthermore, the improved MPPT tactic can significantly enhance the tracking efficiency of the existing MPPT methods.

\section{Data Availability}

Data are available on request.

\section{Conflicts of Interest}

The authors declare that there is no conflict of interest regarding the publication of this paper.

\section{References}

[1] REN21, Renewables 2010 Global Status Report, REN21 Secretariat, Paris, 2010.

[2] P. Singh and N. M. Ravindra, "Temperature dependence of solar cell performance - an analysis," Solar Energy Materials \& Solar Cells, vol. 101, pp. 36-45, 2012.

[3] D. L. King, J. A. Kratochvil, and W. E. Boyson, "Temperature coefficients for PV modules and arrays: measurement methods, difficulties, and results," in Conference Record of the Twenty Sixth IEEE Photovoltaic Specialists Conference - 1997, Anaheim, CA, USA, 1997.

[4] S. Saravanan and B. N. Ramesh, "Maximum power point tracking algorithms for photovoltaic system - a review," Renewable and Sustainable Energy Reviews, vol. 57, pp. 192204, 2016.

[5] T. Esram and P. L. Chapman, "Comparison of photovoltaic array maximum power point tracking techniques," IEEE Transactions on Energy Conversion, vol. 22, no. 2, pp. 439449, 2007.

[6] M. A. G. De Brito, L. Galotto, L. P. Sampaio, M. G. De Azevedo, and C. A. Canesin, "Evaluation of the main MPPT techniques for photovoltaic applications," IEEE Transactions on Industrial Electronics, vol. 60, no. 3, pp. 1156-1167, 2013.

[7] N. Femia, G. Petrone, G. Spagnuolo, and M. Vitelli, "Optimization of perturb and observe maximum power point tracking method," IEEE Transactions on Power Electronics, vol. 20, no. 4, pp. 963-973, 2005.

[8] M. A. Elgendy, B. Zahawi, and D. J. Atkinson, "Operating characteristics of the $\mathrm{P} \& \mathrm{O}$ algorithm at high perturbation frequencies for standalone PV systems," IEEE Transactions on Energy Conversion, vol. 30, no. 1, pp. 189-198, 2015.

[9] A. Safari and S. Mekhilef, "Simulation and hardware implementation of incremental conductance MPPT with direct control method using cuk converter," IEEE Transactions on Industrial Electronics, vol. 58, no. 4, pp. 1154-1161, 2011.

[10] K. S. Tey and S. Mekhilef, "Modified incremental conductance MPPT algorithm to mitigate inaccurate responses under fastchanging solar irradiation level," Solar Energy, vol. 101, pp. 333-342, 2014.
[11] W. Xiao and W. G. Dunford, "A modified adaptive hill climbing MPPT method for photovoltaic power systems," in 2004 IEEE 35th Annual Power Electronics Specialists Conference (IEEE Cat. No.04CH37551), vol. 3, Aachen, Germany, 2004.

[12] F. Liu, S. Duan, F. Liu, B. Liu, and Y. Kang, "A variable step size INC MPPT method for PV systems," IEEE Transactions on Industrial Electronics, vol. 55, no. 7, pp. 2622-2628, 2008.

[13] Q. Mei, M. Shan, L. Liu, and J. M. Guerrero, "A novel improved variable step-size incremental-resistance MPPT method for PV systems," IEEE Transactions on Industrial Electronics, vol. 58, no. 6, pp. 2427-2434, 2011.

[14] X. Li, H. Wen, and W. Xiao, "A modified MPPT technique based on the MPP-locus method for photovoltaic system," in IECON 2017 - 43rd Annual Conference of the IEEE Industrial Electronics Society, Beijing, China, 2017.

[15] X. Li, H. Wen, L. Jiang, W. Xiao, Y. Du, and C. Zhao, "An improved MPPT method for PV system with fast-converging speed and zero oscillation," IEEE Transactions on Industry Applications, vol. 52, no. 6, pp. 5051-5064, 2016.

[16] X. Li, H. Wen, L. Jiang, Y. Hu, and C. Zhao, "An improved beta method with autoscaling factor for photovoltaic system," IEEE Transactions on Industry Applications, vol. 52, no. 5, pp. 42814291, 2016.

[17] H. Chaieb and A. Sakly, "A novel MPPT method for photovoltaic application under partial shaded conditions," Solar Energy, vol. 159, pp. 291-299, 2018.

[18] L. K. Letting, J. L. Munda, and Y. Hamam, "Optimization of a fuzzy logic controller for PV grid inverter control using Sfunction based PSO," Solar Energy, vol. 86, no. 6, pp. 16891700, 2012.

[19] T. K. Soon and S. Mekhilef, "A fast-converging MPPT technique for photovoltaic system under fast-varying solar irradiation and load resistance," IEEE Transactions on Industrial Informatics, vol. 11, no. 1, pp. 176-186, 2015.

[20] K. Swaraj, A. Mohapatra, and S. S. Sahoo, "Combining PV MPPT algorithm based on temperature measurement with a PV cooling system," in 2016 International Conference on Signal Processing, Communication, Power and Embedded System (SCOPES), Paralakhemundi, India, 2017.

[21] Y. Wang, Y. Yang, G. Fang et al., "An advanced maximum power point tracking method for photovoltaic systems by using variable universe fuzzy logic control considering temperature variability," Electronics, vol. 7, no. 12, p. 355, 2018.

[22] C. Abdelkhalek, E. L. B. Said, and A. Younes, "An improved MPPT tactic for PV system under temperature variation," in 2019 8th International Conference on Systems and Control (ICSC), Marrakesh, Morocco, 2019.

[23] V. J. Fesharaki, M. Dehghani, J. J. Fesharaki, and H. Tavasoli, "The effect of temperature on photovoltaic cell efficiency," in Proceeding 1st Int Conf Emerg Trends Energy Conserv, 2011.

[24] M. K. El-Adaw, S. A. Shalaby, S. E. S. Abdl El-Ghany, and M. A. Attallah, "Effect of solar cell temperature on its photovoltaic conversion efficiency," International Journal of Scientific and Engineering Research, vol. 6, 2015.

[25] G. Li, Q. Xuan, G. Pei, Y. Su, and J. Ji, "Effect of non-uniform illumination and temperature distribution on concentrating solar cell - a review," Energy, vol. 144, pp. 1119-1136, 2018.

[26] A. Khatibi, F. Razi Astaraei, and M. H. Ahmadi, "Generation and combination of the solar cells: a current model review," Energy Sci Eng, vol. 7, no. 2, pp. 305-322, 2019. 
[27] M. A. Husain, A. Tariq, S. Hameed, A. M. S. Bin, and A. Jain, "Comparative assessment of maximum power point tracking procedures for photovoltaic systems," Green Energy Environ, vol. 2, no. 1, pp. 5-17, 2017.

[28] T. Ngo and S. Santoso, "Grid-connected photovoltaic converters: topology and grid interconnection," J Renew Sustain Energy, vol. 6, no. 3, 2014.

[29] Y. Zhu, M. K. Kim, and H. Wen, "Simulation and analysis of perturbation and observation-based self-adaptable step size maximum power point tracking strategy with low power loss for photovoltaics," Energies, vol. 12, no. 1, p. 92, 2019.

[30] M. Valentini, A. Raducu, D. Sera, and R. Teodorescu, "PV inverter test setup for European efficiency, static and dynamic MPPT efficiency evaluation," in 2008 11th International Conference on Optimization of Electrical and Electronic Equipment, Brasov, Romania, 2008. 